\title{
Discovery of calcium-metal alloy anodes for reversible Ca-ion batteries
}

\author{
Zhenpeng Yao, ${ }^{12}$ Vinay I. Hegde, ${ }^{2}$ Alán Aspuru-Guzik, ${ }^{1345^{*}}$ Chris Wolverton ${ }^{2 *}$ \\ ${ }^{1}$ Department of Chemistry and Chemical Biology, Harvard University, 12 Oxford Street, \\ Cambridge, Massachusetts 02138, United States \\ ${ }^{2}$ Department of Materials Science and Engineering, Northwestern University, 2220 Campus \\ Drive, Evanston, Illinois 60208, United States \\ ${ }^{3}$ Department of Chemistry and Department of Computer Science, University of Toronto, Toronto, \\ Ontario M5S 3H6, Canada \\ ${ }^{4}$ Vector Institute for Artificial Intelligence, Toronto, Ontario M5S 1M1, Canada \\ ${ }^{5}$ Canadian Institute for Advanced Research (CIFAR) Senior Fellow, Toronto, Ontario M5S 1M1, \\ Canada \\ *Correspondence: alan@aspuru.com*Correspondence: c-wolverton@northwestern.edu
}

\begin{abstract}
Ca-ion batteries (CIBs) show promise to achieve the high energy density required by emerging applications like electric vehicles because of their potentially improved capacities and high operating voltages. The development of CIBs has been hindered by the failure of traditional graphite and calcium metal anodes due to the intercalation difficulty and lacking efficient electrolyte. Recently a high voltage ( $4.45 \mathrm{~V}) \mathrm{CIB}$ cell using $\mathrm{Sn}$ as the anode was reported achieving a remarkable cyclability (> 300 cycles). The calciation of $\mathrm{Sn}$ was observed to end at $\mathrm{Ca}_{7} \mathrm{Sn}_{6}$, which is surprising, since higher Ca-content compounds are known (e.g. $\left.\mathrm{Ca}_{2} \mathrm{Sn}\right)$. Here, we investigate computationally the $\mathrm{Sn}$ electrochemical calciation reaction process and explore the reaction
\end{abstract}


driving force as a function of Ca content using density functional theory (DFT) calculations. This exploration allows us to identify threshold voltages which govern the limits of the calciation process. We then use this information to design a four-step screening strategy and use highthroughput DFT to search for anode materials with higher properties. We predict that many metalloids ( $\mathrm{Si}, \mathrm{Sb}, \mathrm{Ge})$, (post-)transition metals ( $\mathrm{Al}, \mathrm{Pb}, \mathrm{Cu}, \mathrm{Cd}, \mathrm{CdCu}_{2}$ ) are promising inexpensive anode candidates and warrant further experimental investigations.

\section{Introduction}

The usage of renewable energy, coupled with the growing application of electric vehicles (EVs), demand energy storage techniques with high energy density and low cost. ${ }^{1}$ Multivalent batteries, like $\mathrm{Mg}$-ion, ${ }^{2} \mathrm{Ca}$-ion, ${ }^{3,4}$ and Al-ion batteries, ${ }^{5,6}$ have the potential to realize significantly improved capacities, compared to monovalent batteries (e.g. Li-ion batteries), due to more electrons carried per ion. Among them, Ca-ion batteries (CIB) have drawn special attention with merits besides the capacity enhancement: 1) $\mathrm{Ca} / \mathrm{Ca}^{2+}$ has a reduction potential $(-2.87 \mathrm{~V})$ only slightly higher than $\mathrm{Li} / \mathrm{Li}^{+}(-3.04 \mathrm{~V})$, yet much lower than $\mathrm{Mg} / \mathrm{Mg}^{2+}(-2.36 \mathrm{~V})$ and $\mathrm{Al} / \mathrm{Al}^{3+}(-1.68$ V), which provides CIB the prospect to function at voltages comparable with Li-ion batteries and much higher than the counterparts of $\mathrm{Mg}$-ion and $\mathrm{Al}$-ion batteries. ${ }^{7,8}$ 2) $\mathrm{Ca}$ is the $5^{\text {th }}$ most abundant element in the earth's crust with an extensive global resource distribution, in contrast to lithium. 3) The kinetics of $\mathrm{Ca}$-ion in solid electrodes are faster than $\mathrm{Mg}$ - and Al-ions due to reduced charge density. ${ }^{9-11}$

The development of CIBs was originally pioneered by the study of Ca-ion electrochemical intercalations into layered transition metal oxides and sulfides. ${ }^{12}$ Subsequently, many efforts then were made to search for cathode materials which will tolerate a large amount of Ca-ions reversibly extracted/re-accommodated upon charge/discharge. Material systems including Prussian blue 
compounds, ${ }^{10,13,14}$ Chevrel phases, ${ }^{15,16}$ spinels, ${ }^{17-19}$ perovskites,${ }^{20}$ layered transition metal (TM) sulfides, ${ }^{21}$ and iron phosphate, ${ }^{22}$ were suggested to be effective Ca-ion electrodes with the spinels and perovskites attracting extra attention because of their predicted high voltage $(>3.5 \mathrm{~V})$ and large theoretical capacities $(>240 \mathrm{mAh} / \mathrm{g})$ during discharge at room temperature. ${ }^{17-20}$ Distinct from these TM based electrodes, a graphite cathode has been reported which functions via the (de-)intercalation of electrolyte salt anions $\left(\mathrm{A}^{-}=\mathrm{PF}_{6}^{-}, \mathrm{ClO}_{4}{ }^{-}\right.$and so on) upon charge/discharge at remarkably high voltages $(5.2 \mathrm{~V})^{23,24}$ with a theoretical capacity as high as $372 \mathrm{mAh} / \mathrm{g}$ (corresponding to $\mathrm{AC}_{6}$ ). ${ }^{25,26}$ Yet the practical capacity of batteries based on this material suffer from a large degradation $(\sim 90 \mathrm{mAh} / \mathrm{g})$ as a result of the electrolyte decomposition under high voltage. $^{26}$

Unlike the continuous development of CIB cathode materials, studies focusing on anodes have been relatively scarce. Graphite based CIB anodes have been shown to be problematic at room temperature due to difficulties related to the intercalation of calcium. ${ }^{27}$ The pursuit of a calcium metal anode is currently hindered by the lack of an effective electrolyte to plate/strip calcium metal at room temperature ${ }^{3}$ in an adequate voltage window. ${ }^{4}$ Also, $\mathrm{Ca}^{2+}$ diffusion is observed to be extremely sluggish through the as-formed solid electrolyte interphase (SEI) between the calcium metal anode and the electrolyte. ${ }^{28,29} \mathrm{TM}$ oxide $\left(\text { i.e. } \mathrm{V}_{2} \mathrm{O}_{5}\right)^{30}$ based anodes have been shown to be effective at storing Ca-ions; however, the high calciation potential $(\sim 2.8 \mathrm{~V})$ of this material significantly reduces the overall output voltage of the whole cell. ${ }^{17}$

Alloying-type anodes, widely studied for Li-ion batteries, show great promise for reversible CIBs. Using a Sn anode and graphite cathode, Wang et al. ${ }^{14}$ recently reported a high voltage $(4.45 \mathrm{~V}) \mathrm{CIB}$ cell with a reasonable capacity of $85 \mathrm{mAh} / \mathrm{g}$ and a remarkable cyclability (95\% capacity retention in 350 cycles). Besides $\mathrm{Sn}$, several metals and metalloids including $\mathrm{Zn}$, 
$\mathrm{Al}, \mathrm{Si}, \mathrm{Li}$, and $\mathrm{Na}$ also have been investigated for the use of alloying-type CIBs anodes with largely disparate capacities achieved..$^{13,14,31,32}$ All of them except Na have been reported to mix with Ca in wide composition ranges, forming various intermetallic compounds. ${ }^{33}$ For instance, the highest Ca-content intermetallic compounds of $\mathrm{Sn}, \mathrm{Zn}$, and $\mathrm{Li}$ are $\mathrm{Ca}_{2} \mathrm{Sn},{ }^{34} \mathrm{Ca}_{3} \mathrm{Zn}^{35}$ and $\mathrm{CaLi}_{2},{ }^{36}$ with corresponding theoretical capacities calculated to be $903 \mathrm{mAh} / \mathrm{g}, 1366 \mathrm{mAh} / \mathrm{g}$, and $3860 \mathrm{mAh} / \mathrm{g}$. However, in experimental full cell operations, the calciation of $\mathrm{Sn}$ ends at $\mathrm{Ca}_{7} \mathrm{Sn}_{6}$ with a theoretical capacity of $527 \mathrm{mAh} / \mathrm{g}$ while the calciations of $\mathrm{Zn}$ and $\mathrm{Li}$ are even more truncated with very limited capacity observed. ${ }^{14}$ It is therefore important to examine the metal-calcium (M-Ca) reaction mechanisms during the electrochemical calciation and understand the variation of the calciation driving force as a function of Ca-ions accommodated. Furthermore, considering that $\mathrm{Ca}$ mixes with many metals and metalloids, forming a wide range of alloys and compounds, ${ }^{33}$ it is then of significant interest to explore the whole alloying space of M-Ca systems and discover novel active anode materials for improved electrochemical properties and cyclabilities.

First-principles density functional theory (DFT) calculations have been extensively used as compelling tools to study the battery materials by understanding the underlying mechanisms, ${ }^{37-}$ 41 exploring the kinetics during electrochemical reactions, ${ }^{42-45}$ and predicting novel highperformance electrode materials. ${ }^{46-49}$ Here in this work, we use DFT to investigate the Sn-Ca electrochemical alloy reaction process via constructing the ground state $\mathrm{Sn}$-Ca phase diagram and explore the reaction driving force evolution as a function of $\mathrm{Ca}$-ion accommodated. We then identify the convex hull characteristics favored by large capacity alloy-type anodes and by comparison between our DFT calculations and electrochemical measurements of CIB cells, we define threshold calciation voltages which limit the extent of calciation reactions in real cells by examining the alloy reaction of $\mathrm{Ca}$ and $\mathrm{Zn}, \mathrm{Li}, \mathrm{Na}$. Moreover, we design a four-step screening 
strategy and use high-throughput DFT calculations to explore all M-Ca alloying space to search for anode materials with higher energy density and constrained volume expansion. We predict that many metalloids ( $\mathrm{Si}, \mathrm{Sb}, \mathrm{Ge}$ ), (post-)transition metals (Al, $\mathrm{Pb}, \mathrm{Cu}, \mathrm{Cd}, \mathrm{CdCu}_{2}, \mathrm{Ga}, \mathrm{Bi}, \mathrm{In}, \mathrm{Tl}, \mathrm{Hg}$ ), and noble metals (Ag, $\mathrm{Au}, \mathrm{Pt}, \mathrm{Pd})$ are promising anode candidates. Our discoveries shed light on the design of high performance reversible $\mathrm{Ca}$-ion batteries and provide predictions of new compounds awaiting experimental validation.

\section{Methodology}

\subsection{First-principles DFT calculations}

All the first-principles calculations were performed via the Vienna Ab-initio Simulation Package (VASP) $)^{50-53}$ within the projector augmented wave (PAW) formalism ${ }^{54}$ and the PerdewBecke-Ernzerhof (PBE) approximation ${ }^{55}$ to the exchange-correlation potential was employed. We used a plane wave basis with a cutoff energy of $520 \mathrm{eV}$ and $\boldsymbol{\Gamma}$-centered $k$-meshes with a density of $8000 k$-points per reciprocal atom. All the calculations reported in this study were conducted under the framework of the Open Quantum Materials Database (OQMD). ${ }^{56,57}$

\subsection{Voltage profile calculations: calciation voltage and output voltage}

\subsubsection{Calciation voltage $V$ of $\mathrm{M}-\mathrm{Ca}$ anode}

We evaluated the averaged $\mathrm{M}-\mathrm{Ca}$ electrochemical alloy reaction voltages (calciation voltage, relative to $\mathrm{Ca} / \mathrm{Ca}^{2+}$ ) by calculating the reaction free energy per $\mathrm{Ca}$ added/removed, as shown in Eq. 1:58,59

$$
V=\frac{\Delta G_{\mathrm{f}}}{2 F \Delta N_{\mathrm{Ca}}}
$$

where $F$ is the Faraday constant, $\Delta N_{\mathrm{Ca}}$ is the amount of Ca added/removed, 2 is the amount of charges carried per single $\mathrm{Ca}$, and $\Delta G_{\mathrm{f}}$ is the molar free energy change during the reaction. 
Assuming that the calciation proceeds through a two-phase reaction between $\mathrm{Ca}_{x} \mathrm{M}$ and $\mathrm{M}: \mathrm{M}+$ $x \mathrm{Ca} \rightarrow \mathrm{Ca}_{x} \mathrm{M}, \Delta G_{\mathrm{f}}$ can be approximated by the total internal energy changes from DFT calculations $(0 \mathrm{~K})$,

$$
\Delta E=E\left(\mathrm{Ca}_{x} \mathrm{M}\right)-E(\mathrm{M})-x E\left(\mathrm{Ca}_{\text {metal }}\right)
$$

where $E\left(\mathrm{Ca}_{x} \mathrm{M}\right)$ and $E(\mathrm{M})$ are the DFT energies at the respective compositions. We neglected entropic contributions and the reaction voltage profiles therefore will follow the $\mathrm{T}=0 \mathrm{~K}$ ground state convex hull and consist of a series of constant voltage steps along the two-phase regions of the convex hull, separated by discontinuities indicating the single phase compounds on the hull. It is noteworthy that electrochemical M-Ca reactions do not necessarily proceed through two-phase reactions in practice. Thus, the calculated $\mathrm{T}=0 \mathrm{~K}$ voltage profiles should be viewed as an approximation to the actual voltage profiles. ${ }^{60,61}$ The voltage drops in the profile become more rounded at finite temperatures (e.g., room temperature), due to finite temperature effects. ${ }^{59}$

\subsubsection{Output voltage $V_{\text {output }}$ of CIBs using the M-Ca anode}

During the discharge of CIBs, the M-Ca alloy anode, which is the focus of this study, experiences a decalciation reaction (corresponding voltage: $-V$ ) while the corresponding cathode experiences a calciation reaction (corresponding voltage: $V_{\text {cathode }}$ ). Upon charging, the reverse reactions occur. The output voltage of a complete CIB cell containing both cathode and anode upon discharge then can be defined as follows:

$$
V_{\text {output }}=V_{\text {cathode }}-V
$$

where the anode voltage $V$ can be calculated using Eq. 1. To calculate the output voltage and then evaluate the energy densities of CIBs using anodes discovered in this study, we assume a value of $V_{\text {cathode }}=5.2 \mathrm{~V}$, consistent with the recent report of a graphite-based cathode material. ${ }^{24}$ 
We favor anodes with lower calciation voltage $V$ to maximize the $V_{\text {output }}$ of CIB, yet $V$ should not be too low to ensure enough driving force for the reversed calciation reaction to happen on charge.

\subsection{Volume expansion evaluations}

We computed the volume expansion upon the calciation of $\mathrm{M}$ via calculating the volume change per $\mathrm{Ca}$ added as shown in Eq. 3:

$$
U=\frac{u_{C a_{x} M}-u_{M}}{x}
$$

where $u_{\mathrm{Ca}_{x} \mathrm{M}}$ and $u_{\mathrm{M}}$ are the volumes of $\mathrm{Ca}_{x} \mathrm{M}$ and $\mathrm{M}$ respectively, $x$ is the amount of $\mathrm{Ca}$.

\subsection{Capacity and energy density calculations}

The gravimetric and volumetric capacity of M-Ca alloy anode corresponding to a given voltage plateau (a given two-phase reaction) can be calculated according to following equations Eq. 5 and Eq. 6:

$$
\begin{aligned}
& C_{g}(V)=\frac{2 \Delta N_{\mathrm{Ca}}(\eta) F}{m_{M}} \\
& C_{u}(V)=\frac{2 \Delta N_{\mathrm{Ca}}(\eta) F}{u_{M}}
\end{aligned}
$$

where $F$ is the Faraday constant, $\Delta N_{\mathrm{Ca}}(V)$ is the amount of $\mathrm{Ca}$ added/removed corresponding to the voltage plateau, 2 is the amount of charge carried per single $\mathrm{Ca}, m_{M}$ and $u_{M}$ are the mass and volume of $\mathrm{M}$, respectively.

The energy density $E_{g}(V)$ and specific energy $E_{u}(V)$ of the CIBs using the M-Ca alloy anode then can be calculated by integrating the volumetric capacity $C_{g}(V)$ and gravimetric capacity $C_{u}(V)$ as a function of output voltage $V_{\text {output }}$ as shown in Eq. 7 and Eq. 8:

$$
E_{g}(V)=\int_{V^{\prime}}^{V_{0}} C_{g}\left(V_{\text {cathode }}-V^{\prime}\right) d V^{\prime}
$$




$$
E_{u}(V)=\int_{V^{\prime}}^{V_{0}} C_{u}\left(V_{\text {cathode }}-V^{\prime}\right) d V^{\prime}
$$

where $V_{0}$ is the lower limit of $\mathrm{M}$ calciation voltage profile.

\section{Results and discussions}

\subsection{Sn-Ca phase diagram and the electrochemical Sn-Ca reactions}

Phase diagrams represent the thermodynamic phase equilibria of multicomponent systems

and provide useful information on the electrochemical reactions between phases. The ground state convex hull represents the $\mathrm{T}=0 \mathrm{~K}$ limit of the thermodynamic phase diagram and gives information about the ground state stability of compounds in a given system. Experimental phasediagram determination for a specific system can be time- and labor- consuming, while it can be significantly accelerated by calculating energies of all the known compounds in the corresponding chemical space using DFT ${ }^{47}$ Here we built $\mathrm{M}-\mathrm{Ca} \mathrm{T}=0 \mathrm{~K}$ phase diagrams using structures with the lowest energy for each composition with $\mathrm{M}$ be metal/metalloids elements and their binary alloys. All the compounds were adopted from the Inorganic Crystal Structure Database (ICSD) ${ }^{62}$ and corresponding calculations were carried out under the framework of OQMD. ${ }^{56,57}$ Using these convex hulls, we analyze the electrochemical calciation process of $\mathrm{Sn}$ and examine the driving force variations to determine the calciation maximums for the $\mathrm{Sn}$ anode. Then we will validate our hypothesis in other typical systems including $\mathrm{Zn}, \mathrm{Li}$, and $\mathrm{Na}$.

The calculated Sn-Ca convex hull is shown in Fig. 1A, we are able to correctly identify all the known intermediate phases in the experimental phase diagram including $\mathrm{CaSn}_{3}, \mathrm{CaSn}, \mathrm{Ca}_{7} \mathrm{Sn}_{6}$, $\mathrm{Ca}_{31} \mathrm{Sn}_{20}, \mathrm{Ca}_{36} \mathrm{Sn}_{23}$, and $\mathrm{Ca}_{2} \mathrm{Sn}$ as either on the hull or slightly ( $<10 \mathrm{meV} /$ atom $)$ above the hull. ${ }^{34}$ The calciation voltages corresponding to these phases declines from $0.99 \mathrm{~V}, 0.72 \mathrm{~V}, 0.59 \mathrm{~V}$, to $0.53 \mathrm{~V}$ relative to $\mathrm{Ca} / \mathrm{Ca}^{2+}$ (Fig. 1B) while the volume expansions of the system per $\mathrm{Ca}$ accommodated increases from $7.4 \AA^{3}, 27.5 \AA^{3}, 27.6 \AA^{3}, 28.8 \AA^{3}, 31.1 \AA^{3}$ (Fig. 1C). By comparison 
with experimental electrochemistry data, we can determine a cutoff for the allowed calciation driving force, below which the reaction will not proceed in practice. For instance, the experimental calciation of $\mathrm{Sn}$ ends at $\mathrm{Ca}_{7} \mathrm{Sn}_{6},{ }^{14}$ and the calculated calciation voltage of the $\mathrm{Sn}-\mathrm{Ca}$ system (Fig. 1B) reaches a value of $0.53 \mathrm{~V}$ (relative to $\mathrm{Ca} / \mathrm{Ca}^{2+}$ ) for $\mathrm{Ca}_{7} \mathrm{Sn}_{6}$. Hence, we use this comparison to hypothesize that the driving force for calciation of anodes should be no less than $0.53 \mathrm{~V}$. We then validate the use this driving force limit to determine the calciation extent of $\mathrm{Zn}, \mathrm{Li}$, and $\mathrm{Na}$ (and other metals), and compare with experimental measurements below. We also note that the shape of the convex hull can have a profound impact on the extent of calciation. The Sn-Ca convex hull features a relatively steep decreasing energy on the Sn-rich side. The fast decrease in formation energy with increasing $\mathrm{Ca}$ content corresponds to high calciation voltages and a large reaction driving force while the "length" (in Ca content) of this segment of the convex hull indicates a large amount of $\mathrm{Ca}$ ions react with the anode when the driving force is large. On the contrary, convex hulls which feature short or shallow decreasing segments on the Ca-poor side indicate a weak driving force, or small Ca capacity, and potentially point to a hasty end to calciation.

\subsection{Ca-Zn, Li, Na phase diagrams and the electrochemical calciation limits}

Having determined a calciation voltage threshold in the Sn-Ca system, we next construct convex hulls in the Zn-Ca, Li-Ca, and Na-Ca systems, as shown in Fig. 2A. The DFT calculations show nearly all experimentally observed intermediate compounds on the hull (except $\mathrm{CaZn}_{3}$ which we exclude because its reported crystal structure exhibits partial occupancies). Na is reported to show no solubility in $\mathrm{Ca}$ with no intermetallic compound reported. As a simple test of the immiscibility and lack of compound formation in this system, we used $\mathrm{Li}_{2} \mathrm{Ca}$ as a prototype and calculate the corresponding $\mathrm{Na}_{2} \mathrm{Ca}$ energy. The phase is above the hull, consistent with the lack of observed compounds in this system. The $\mathrm{Zn}$-Ca convex hull is asymmetric with low energies on 
the $\mathrm{Zn}$-rich side, and formation energy of $\mathrm{Ca}_{x} \mathrm{Zn}$ rapidly decreases for small $\mathrm{Ca}$ concentrations $(0$ $<x<0.33$ ). As a result, the calciation voltage quickly falls from $1.03 \mathrm{~V}$ to $0.46 \mathrm{~V}$ (Fig. $2 \mathrm{~B}$ ) in the same concentration range. If we apply the calciation voltage threshold derived from the $\mathrm{Sn}-\mathrm{Ca}$ system $(0.53 \mathrm{~V})$ to the $\mathrm{Zn}-\mathrm{Ca}$ system, then we would predict its calciation should end at $x=0.167$ $\left(\mathrm{CaZn}_{5}\right)$ and before $x=0.33\left(\mathrm{CaZn}_{2}\right)$, indicating a very limited calciation and capacity. These predictions are consistent with experimental observations, ${ }^{14}$ thus validating the use of the calciation voltage threshold. $\mathrm{Zn}$ also exhibits a larger volume expansion per $\mathrm{Ca}$ of $31.26 \AA^{3}$ than Sn started at an early calciation step $(x=0.167)$ as shown in Fig. 2C. For the calciation reaction of Li, because the convex hull is extremely shallow with very small (negative) formation energies, and thus a low calciation voltage of $0.03 \mathrm{~V}$ (Fig. 2B). The Li-Ca calciation voltage is therefore significantly lower than the threshold calciation voltage value $(0.53 \mathrm{~V})$, and hence is predicted to exhibit very low reversible capacity, also in agreement with experimental observations, ${ }^{14}$ and therefore validating the use of the threshold. For $\mathrm{Na}$, no solubility in $\mathrm{Ca}$ and no stable intermediate phases, agrees with its poor calciation performance observed. ${ }^{14}$ In order to obtain a significant calciation capacity, one should search for M-Ca convex hulls with long and fast decreasing segments to the M-rich side to ensure large capacity with a high driving force. Having validated our strategy, we next use our threshold calciation voltage combined with high-throughput (HT) DFT of a large number of alloying-type anode calciation reactions to discover novel anodes with promising electrochemical properties.

\subsection{HT-DFT screening for high-performance novel calcium alloy anodes}

$\mathrm{Ca}$ forms alloys with many metals and metalloids. ${ }^{33}$ We use this fact, along with the threshold calciation voltage above to design a four-step screening strategy and apply it to search for the high electrochemical property anodes as shown in Fig. 3. The four steps are: (i) The 
screening was initiated by identifying all the binary and ternary $\mathrm{Ca}$ intermetallic compounds from the Inorganic Crystal Structure Database (ICSD). ${ }^{62}$ We exclude quaternary or higher order Ca alloys because of the potentially more complex mass transport (and hence sluggish kinetics) during their calciation and decalciation. In total, we identify unique $357 \mathrm{M}$-Ca compounds. (ii) We then examined all the $\mathrm{Ca}_{x} \mathrm{M}$ compounds and checked the existence of counterparts with the same stoichiometry, but with Ca removed, i.e., M. If both of them exist in the ICSD, the $\mathrm{Ca}_{x} \mathrm{M}$ compound is then can be seen as the calciation product of $\mathrm{M}$ where this latter compound is either simply a metal/metalloid element (e.g. Sn) or a binary intermetallic compound $\mathrm{M}_{a} \mathrm{M}_{b}{ }_{b}(e . g$. $\mathrm{CuAu})$. This screen results in a pool of $115 \mathrm{M}-\mathrm{Ca}$ systems with a various number of calciation reactions. (iii) Next, we calculated calciation voltage profiles for calciation reactions of all $115 \mathrm{M}$-Ca systems as summarized in Fig. 4. To determine the practical extent of the calciation reactions of each M-Ca system and also its maximum capacity, we apply threshold calciation voltages to all the $\mathrm{M}-\mathrm{Ca}$ systems. Two factors were considered to define the threshold calciation voltages: calcium metal plating and the practical calciation limit (discussed above). Anodes calciation potentials lower than $\mathrm{Ca} / \mathrm{Ca}^{2+}$, can experience calcium metal plating and possible dendrite formation, leading to possible short circuit and safety concerns. Therefore, we apply a first threshold calciation voltage of $0.1 \mathrm{~V}$, which we term a "relaxed criterion", to avoid calcium plating and potential failure of the cell. Meanwhile, we also apply a second threshold calciation voltage of $0.53 \mathrm{~V}$, obtained by determining the practical Sn calciation maximum as discussed above. The calciation driving force requirements for M-Ca systems could be different from Sn-Ca (although we validated this strategy above for Zn-Ca, Na-Ca, and Li-Ca systems), yielding some uncertainty in the predictions. Hence, we use both thresholds with $0.53 \mathrm{~V}$ serving as the restrictive criterion and the $0.1 \mathrm{~V}$ serving as the relaxed criterion. We repeated each screening calculation with both thresholds to illustrate the changes that 
could occur with a range of calciation thresholds. Then two capacity maximums $\left(\mathrm{C}_{\max }\right)$ of each $\mathrm{M}-$ Ca system are determined. (iv) For the two data sets obtained with different threshold calciation voltages, we estimated their output voltages refer to the $V_{\text {cathode }}$ assumed, volume expansions, specific energies, and energy densities and rank them using their maximum capacities and energy densities. Cyclabilities of alloying-type anodes are usually deteriorated by a large volume expansion due to ion insertions as we learned from the Li-ion batteries ${ }^{63}$ and M-Ca systems with lower volume expansions are then favored. We then screen for M-Ca systems with a higher energy density than Sn, yielding a list of the most promising anode candidates.

\subsubsection{Anode candidates obtained with the relaxed calciation voltage criterion}

Metalloids (Si, Ge, As, Sb)

Our screening strategy identifies metalloids including $\mathrm{Si}, \mathrm{Ge}, \mathrm{As}$, and $\mathrm{Sb}$ as compelling anode materials with high specific energies and remarkably constrained volume expansions as shown in Fig. 5. Among them, Si exhibits the highest gravimetric capacity $(3817 \mathrm{mAh} / \mathrm{g})$ and specific energy $(18495 \mathrm{Wh} / \mathrm{kg}$, calculated with graphite cathode usage assumed as discussed in Section 2.4) in this study by taking as many as $2 \mathrm{Ca}$. These attributes are significantly larger than the analogous properties of $\mathrm{Sn}(903 \mathrm{mAh} / \mathrm{g}, 4216 \mathrm{Wh} / \mathrm{kg})$ when the lower threshold calciation voltage is applied. The average calciation voltage for the $\mathrm{Si}$ anode, $0.35 \mathrm{~V}$, is modest. Meanwhile, its maximum volume expansion is $31.89 \AA^{3}$ per $\mathrm{Ca}$ and is comparable to $\mathrm{Sn}\left(31.13 \AA^{3}\right.$ per $\left.\mathrm{Ca}\right)$. Ge, $\mathrm{As}$ and $\mathrm{Sb}$ also can take a maximum amount of $2 \mathrm{Ca}$ per $\mathrm{M}$ when the low threshold calciation voltage was applied, and their heavier masses make their gravimetric capacities $(1476 \mathrm{mAh} / \mathrm{g}$, $1431 \mathrm{mAh} / \mathrm{g}, 880 \mathrm{mAh} / \mathrm{g})$ and specific energies $(6980 \mathrm{Wh} / \mathrm{kg}, 6371 \mathrm{Wh} / \mathrm{kg}, 3985 \mathrm{Wh} / \mathrm{kg}$ ) slightly lower than Si, yet still comparable or higher than $\mathrm{Sn}$. Moreover, Ge, As and Sb exhibit much lower volume expansion maximums than $\mathrm{Sn}: 31.06 \AA^{3}, 30.93 \AA^{3}, 29.66 \AA^{3}$ per Ca. 
Post-transition metals ( $\mathrm{Ga}, \mathrm{Al}, \mathrm{In}, \mathrm{Tl}, \mathrm{Pb}, \mathrm{Hg}, \mathrm{Cd}, \mathrm{Zn}$ )

Post-transition metals contain candidates among which several have been investigated experimentally as anodes of CIBs such as Sn, Al, Zn. Boron-group metals including Ga, and Al exhibit attractive properties as alloy anodes for CIB because of their second and third highest specific energies $(9746 \mathrm{Wh} / \mathrm{kg}, 9071 \mathrm{Wh} / \mathrm{kg}$ ) predicted in this study (following Si) as well as outstanding gravimetric and volumetric capacities. Moreover, $\mathrm{Al}$ has a potentially low cost making it appealing for practical use in CIBs. The other two boron-group candidates (i.e. In and Tl) also can accommodate significant amounts of $\mathrm{Ca}\left(\mathrm{Ca}_{3} \mathrm{In}, \mathrm{Ca}_{3} \mathrm{Tl}\right)$ and exhibit high volumetric properties (Tab. 1) with volume expansions much lower than $\mathrm{Ga}$ and $\mathrm{Al}$. Similar to $\mathrm{In}$ and $\mathrm{Tl}, \mathrm{Pb}$ can accommodate $3 \mathrm{Ca}$ per atom upon calciation with higher volumetric properties than $\mathrm{Sn}$ and the lowest volume expansion predicted in this study of $28.10 \AA^{3}$ per Ca, indicating the possibility of superior cycling performance than other candidates. $\mathrm{Hg}$ has been tried as liquid-state anode for CIB because of its low melting point, however, there are many intermetallic compounds in the Ca$\mathrm{Hg}$ system that are stable at room temperature. ${ }^{64}$ Thus to use $\mathrm{Hg}$ as an anode in a practical CIB, one could start with the lowest Ca-content compound of $\mathrm{CaHg}_{3}{ }^{64}$ and control the extent of decalciation to avoid the formation of liquid $\mathrm{Hg}$ metal. $\mathrm{CaHg}_{3}$ has slightly lower gravimetric properties than $\mathrm{Sn}$ yet much higher volumetric capacity $(7662 \mathrm{mAh} / \mathrm{mL})$ and energy density (38923 Wh/L). Cd has been widely used in rechargeable NiCd batteries and here, we predict it to be a promising candidate for CIB with higher volumetric capacity $(6227 \mathrm{mAh} / \mathrm{mL})$ and energy density (30778 Wh/L) than $\mathrm{Sn} . \mathrm{Zn}$ as an anode has been reported to fail ${ }^{14}$ because of the rapid decreasing driving force in a very limited calciation concentration range.

Transition metal and alloys (Cu, $\mathrm{CdCu}$ ) 
$\mathrm{Cu}$ and $\mathrm{CdCu}_{2}$ feature improved energy densities compared to $\mathrm{Sn}(5637 \mathrm{Wh} / \mathrm{kg}, 4249$ $\mathrm{Wh} / \mathrm{kg}$ ). Meanwhile, $\mathrm{Cu}$ and its alloys have remarkable electrical conductivity which is a promising attribute for potential high-rate electrodes. In addition, their competitive costs which make them attractive for further experimental validations.

Noble metals (Pd, Au, Pt, Ag)

Noble metal candidates $(\mathrm{Pd}, \mathrm{Au}, \mathrm{Pt})$ exhibit the highest volumetric capacities (18141 $\mathrm{mAh} / \mathrm{mL}, 15830 \mathrm{mAh} / \mathrm{mL}, 14738 \mathrm{mAh} / \mathrm{mL})$ and energy densities $(88853 \mathrm{Wh} / \mathrm{L}, 77078 \mathrm{Wh} / \mathrm{L}$, $69208 \mathrm{Wh} / \mathrm{L})$ in this study by taking significant amount of $\mathrm{Ca}$ per metal $\left(\mathrm{Ca} 3 \mathrm{Pd}, \mathrm{Ca}_{3} \mathrm{Au}, \mathrm{Ca}_{5} \mathrm{Pt}_{2}\right)$. The calciation of $\mathrm{Pd}, \mathrm{Au}$, and $\mathrm{Pt}$ also occur at quite high calciation voltages for a large concentration range (Tab. S1) which ensure large reaction driving forces. Ag also shows improved volumetric properties compared to $\mathrm{Sn}$ at relatively lower potential $(0.24 \mathrm{~V})$. Moreover, the noble metals' superior electrical conductivity and chemical stability against corrosion make them attractive candidates to be explored for CIB anodes. Their relatively high cost (except possibly Ag) may impair their large-scale applications yet their superb predicted properties make them worthy of scientific exploration.

3.3.2 Anode candidates obtained with the restrictive calciation voltage criterion Metalloids (Si, As, Sb, Ge)

Metalloids are still the strongest anode candidates (Fig. 6) even with the strict calciation voltage threshold criterion and concomitant truncated calciation reaction (Tab. S1 and S2). Si, As, $\mathrm{Sb}$ and Ge exhibit highest gravimetric properties (gravimetric capacity: $1908 \mathrm{mAh} / \mathrm{g}, 1431 \mathrm{mAh} / \mathrm{g}$, $880 \mathrm{mAh} / \mathrm{g}, 738 \mathrm{mAh} / \mathrm{g}$; specific energy: $8874 \mathrm{Wh} / \mathrm{kg}, 6371 \mathrm{Wh} / \mathrm{kg}, 3985 \mathrm{Wh} / \mathrm{kg}, 3340 \mathrm{Wh} / \mathrm{kg}$ ) which are significantly higher than $\mathrm{Sn}(527 \mathrm{mAh} / \mathrm{g}, 2426 \mathrm{Wh} / \mathrm{kg})$ while $\mathrm{Si}$ and Ge also show competitive volume expansions $\left(27.6 \AA^{3}, 26.9 \AA^{3}\right.$ per Ca) compared to $\mathrm{Sn}\left(27.59 \AA^{3}\right.$ per $\left.\mathrm{Ca}\right)$. Si 
and $\mathrm{Sb}$ alloy-type anodes have also been extensively investigated in the Li-ion battery field, and their predicted properties suggest further experimental investigation of these anodes in CIB is warranted.

Post-transition metals (Bi)

Most post-transition metals which form alloys with $\mathrm{Ca}$ as discussed in the previous section experience lower calciation voltage compared with the restrictive voltage threshold. Bi emerges under the restrictive voltage threshold to be strong candidate CIB anode because of its comparable gravimetric properties with Sn yet much improved volumetric properties $(5031 \mathrm{mAh} / \mathrm{mL}, 23206$ Wh/L) and constrained volume expansion of $28.37 \AA^{3}$ per Ca.

Noble metals (Pt, Pd, Au)

The noble metals, $\mathrm{Pd}, \mathrm{Au}, \mathrm{Pt}$, have relatively high calciation voltages over wide calciation reaction extents $\left(\mathrm{Ca}_{5} \mathrm{Pt}_{3}, \mathrm{Ca}_{3} \mathrm{Pd}_{2}, \mathrm{Ca}_{5} \mathrm{Au}_{3}\right)$ and large energy densities $(44498 \mathrm{Wh} / \mathrm{L}, 42259 \mathrm{Wh} / \mathrm{L}$, $40824 \mathrm{Wh} / \mathrm{L}$ ) with the strict criterion of $0.53 \mathrm{~V}$. Their large volume expansions also get significantly relieved after the calciation reaction truncations (Tab. S2). Noble metals are still strong candidates for CIBs and scientific exploration.

\section{Conclusions}

In this study, we investigate the $\mathrm{Sn}-\mathrm{Ca}$ electrochemical alloy reaction process via constructing the $\mathrm{Sn}-\mathrm{Ca} \mathrm{T}=0 \mathrm{~K}$ phase diagram and explore the reaction driving force evolution as a function of Ca-ion content accommodated. We identify the convex hull characteristics favored by large capacity alloy-type anodes which are then validated by $\mathrm{Zn}-\mathrm{Ca}, \mathrm{Li}-\mathrm{Ca}$, and $\mathrm{Na}-\mathrm{Ca}$ systems and define threshold voltages to explain and determine the calciation reaction extent. Two threshold voltages are then put forward corresponding to the restrictive and relaxed criterions. The former threshold is based on the observed calciation behavior of $\mathrm{Sn}$, and the latter threshold is 
based on avoiding Ca metal plating and the possibility of dendrite formation. We design a fourstep screening strategy based on voltage thresholds and use high-throughput DFT calculations to explore all M-Ca alloying spaces to search for anode materials with properties superior to the recently reported $\mathrm{Sn}$ anodes. We predict that many metalloids ( $\mathrm{Si}, \mathrm{Sb}, \mathrm{Ge})$, (post-)transition metals (Al, $\mathrm{Pb}, \mathrm{Cu}, \mathrm{Cd}, \mathrm{CdCu}_{2}, \mathrm{Ga}, \mathrm{Bi}, \mathrm{In}, \mathrm{Tl}, \mathrm{Hg}$ ), and noble metals (Ag, $\mathrm{Au}, \mathrm{Pt}, \mathrm{Pd}$ ) are promising anode candidates and worthy of further experimental validation. Our theoretical findings provide insights into the electrochemical calciation reaction process of alloy-type CIB anodes and could help in designing the reversible high-energy density CIB anode materials.

\section{References}

(1) Larcher, D.; Tarascon, J.-M. Towards Greener and More Sustainable Batteries for Electrical Energy Storage. Nat. Chem. 2015, 7 (1), 19-29.

(2) Aurbach, D.; Lu, Z.; Schechter, A.; Gofer, Y.; Gizbar, H.; Turgeman, R.; Cohen, Y.; Moshkovich, M.; Levi, E. Prototype Systems for Rechargeable Magnesium Batteries. Nature 2000, 407 (6805), 724-727.

(3) Ponrouch, A.; Frontera, C.; Bardé, F.; Palacín, M. R. Towards a Calcium-Based Rechargeable Battery. Nat. Mater. 2015, 15 (2), 169-172.

(4) Wang, D.; Gao, X.; Chen, Y.; Jin, L.; Kuss, C.; Bruce, P. G. Plating and Stripping Calcium in an Organic Electrolyte. Nat. Mater. 2017, 17 (1), 16-20.

(5) Lin, M.-C.; Gong, M.; Lu, B.; Wu, Y.; Wang, D.-Y.; Guan, M.; Angell, M.; Chen, C.; Yang, J.; Hwang, B.-J.; et al. An Ultrafast Rechargeable Aluminium-Ion Battery. Nature 2015, 520 (7547), 324-328.

(6) Wang, D.-Y.; Wei, C.-Y.; Lin, M.-C.; Pan, C.-J.; Chou, H.-L.; Chen, H.-A.; Gong, M.; Wu, Y.; Yuan, C.; Angell, M.; et al. Advanced Rechargeable Aluminium Ion Battery with 
a High-Quality Natural Graphite Cathode. Nat. Commun. 2017, 8, 14283-14289.

(7) Gummow, R. J.; Vamvounis, G.; Kannan, M. B.; He, Y. Calcium-Ion Batteries: Current State-of-the-Art and Future Perspectives. Adv. Mater. 2018, 1801702.

(8) Ponrouch, A.; Palacin, M. R. On the Road toward Calcium-Based Batteries. Curr. Opin. Electrochem. 2018.

(9) Nightingale, E. R. Phenomenological Theory of Ion Solvation. Effective Radii of Hydrated Ions. J. Phys. Chem. 1959, 63 (9), 1381-1387.

(10) Gheytani, S.; Liang, Y.; Wu, F.; Jing, Y.; Dong, H.; Rao, K. K.; Chi, X.; Fang, F.; Yao, Y. An Aqueous Ca-Ion Battery. Adv. Sci. 2017, 4 (12), 1700465-1700471.

(11) Muldoon, J.; Bucur, C. B.; Gregory, T. Quest for Nonaqueous Multivalent Secondary Batteries: Magnesium and Beyond. Chem. Rev. 2014, 114 (23), 11683-11720.

(12) Whittingham, M. S. Chemistry of Intercalation Compounds: Metal Guests in Chalcogenide Hosts. Prog. Solid State Chem. 1978, 12 (1), 41-99.

(13) Lipson, A. L.; Pan, B.; Lapidus, S. H.; Liao, C.; Vaughey, J. T.; Ingram, B. J. Rechargeable Ca-Ion Batteries: A New Energy Storage System. Chem. Mater. 2015, 27 (24), 8442-8447.

(14) Wang, M.; Jiang, C.; Zhang, S.; Song, X.; Tang, Y.; Cheng, H.-M. Reversible Calcium Alloying Enables a Practical Room-Temperature Rechargeable Calcium-Ion Battery with a High Discharge Voltage. Nat. Chem. 2018, 10 (6), 667-672.

(15) Smeu, M.; Hossain, M. S.; Wang, Z.; Timoshevskii, V.; Bevan, K. H.; Zaghib, K. Theoretical Investigation of Chevrel Phase Materials for Cathodes Accommodating Ca2+ Ions. J. Power Sources 2016, 306, 431-436.

(16) Rogosic, J. Towards the Development of Calcium Ion Batteries, Massachusetts Institute of 
Technology, 2014.

(17) Cabello, M.; Nacimiento, F.; González, J. R.; Ortiz, G.; Alcántara, R.; Lavela, P.; PérezVicente, C.; Tirado, J. L. Advancing towards a Veritable Calcium-Ion Battery: CaCo2O4 Positive Electrode Material. Electrochem. commun. 2016, 67, 59-64.

(18) Dompablo, M. E. A.; Krich, C.; Nava-Avendaño, J.; Biškup, N.; Palacín, M. R.; Bardé, F. A Joint Computational and Experimental Evaluation of CaMn2O4 Polymorphs as Cathode Materials for Ca Ion Batteries. Chem. Mater. 2016, 28 (19), 6886-6893.

(19) Liu, M.; Rong, Z.; Malik, R.; Canepa, P.; Jain, A.; Ceder, G.; Persson, K. A. Spinel Compounds as Multivalent Battery Cathodes: A Systematic Evaluation Based on Ab Initio Calculations. Energy Environ. Sci. 2015, 8 (3), 964-974.

(20) Arroyo-de Dompablo, M. E.; Krich, C.; Nava-Avendaño, J.; Palacín, M. R.; Bardé, F. In Quest of Cathode Materials for Ca Ion Batteries: The CaMO3 Perovskites ( $\mathrm{M}=\mathrm{Mo}, \mathrm{Cr}$, Mn, Fe, Co, and Ni). Phys. Chem. Chem. Phys. 2016, 18 (29), 19966-19972.

(21) Tchitchekova, D. S.; Ponrouch, A.; Verrelli, R.; Broux, T.; Frontera, C.; Sorrentino, A.; Bardé, F.; Biskup, N.; Arroyo-de Dompablo, M. E.; Palacín, M. R. Electrochemical Intercalation of Calcium and Magnesium in TiS2: Fundamental Studies Related to Multivalent Battery Applications. Chem. Mater. 2018, 30 (3), 847-856.

(22) Lipson, A. L.; Kim, S.; Pan, B.; Liao, C.; Fister, T. T.; Ingram, B. J. Calcium Intercalation into Layered Fluorinated Sodium Iron Phosphate. J. Power Sources 2017, 369, 133-137.

(23) Carlin, R. T.; Long, H. C. De; Fuller, J.; Trulove, P. C. Dual Intercalating Molten Electrolyte Batteries. J. Electrochem. Soc. 1994, 141 (7), L73-L76.

(24) Read, J. A.; Cresce, A. V.; Ervin, M. H.; Xu, K. Dual-Graphite Chemistry Enabled by a High Voltage Electrolyte. Energy Environ. Sci. 2014, 7 (2), 617-620. 
(25) Billaud, D.; Pron, A.; Lincoln Vogel, F. Electrical Resistivity and X-Ray Spacings of Graphite Tetrafluoroborate, Hexafluorophosphate and Hexafluoroantimonate Compounds Synthesized from Nitronium Salts. Synth. Met. 1980, 2 (3-4), 177-184.

(26) Seel, J. A.; Dahn, J. R. Electrochemical Intercalation of PF6- into Graphite. J. Electrochem. Soc. 2000, 147 (3), 892-898.

(27) Emery, N.; Hérold, C.; Lagrange, P. Structural Study and Crystal Chemistry of the First Stage Calcium Graphite Intercalation Compound. J. Solid State Chem. 2005, 178 (9), 2947-2952.

(28) Tchitchekova, D. S.; Monti, D.; Johansson, P.; Bardé, F.; Randon-Vitanova, A.; Palacín, M. R.; Ponrouch, A. On the Reliability of Half-Cell Tests for Monovalent (Li+, $\mathrm{Na}+$ ) and Divalent (Mg2+, Ca2+) Cation Based Batteries. J. Electrochem. Soc. 2017, 164 (7), A1384-A1392.

(29) Aurbach, D.; Skaletsky, R.; Gofer, Y. The Electrochemical Behavior of Calcium Electrodes in a Few Organic Electrolytes. J. Electrochem. Soc. 1991, 138 (12), 35363545 .

(30) Amatucci, G. G.; Badway, F.; Singhal, A.; Beaudoin, B.; Skandan, G.; Bowmer, T.; Plitz, I.; Pereira, N.; Chapman, T.; Jaworski, R. Investigation of Yttrium and Polyvalent Ion Intercalation into Nanocrystalline Vanadium Oxide. J. Electrochem. Soc. 2001, 148 (8), A940-A950.

(31) Tran, T. T.; Obrovac, M. N. Alloy Negative Electrodes for High Energy Density MetalIon Cells. J. Electrochem. Soc. 2011, 158 (12), A1411-A1416.

(32) Ponrouch, A.; Tchitchekova, D.; Frontera, C.; Bardé, F.; Dompablo, M. E. A.; Palacín, M. R. Assessing Si-Based Anodes for Ca-Ion Batteries: Electrochemical Decalciation of 
CaSi2. Electrochem. commun. 2016, 66, 75-78.

(33) Vrana, L. M. Calcium and Calcium Alloys. In Kirk-Othmer Encyclopedia of Chemical Technology; John Wiley \& Sons, Inc.: Hoboken, NJ, USA, 2011; pp 1-10.

(34) Palenzona, A.; Manfrinetti, P.; Fornasini, M. . Phase Diagram of the Ca-Sn System. J. Alloys Compd. 2000, 312 (1-2), 165-171.

(35) Okamoto, H. Ca-Zn (Calcium-Zinc). J. Phase Equilibria Diffus. 2013, 34 (2), 171-171.

(36) Franke, P.; Neuschütz, D.; (SGTE), S. G. T. E. Ca-Li (Calcium - Lithium). In Binary Systems. Part 5: Binary Systems Supplement 1; Springer Berlin Heidelberg: Berlin, Heidelberg; pp 1-3.

(37) Kang, K.; Meng, Y. S.; Bréger, J.; Grey, C. P.; Ceder, G.; Ceder, G. Electrodes with High Power and High Capacity for Rechargeable Lithium Batteries. Science (80-. ). 2006, 311 (5763), 977-980.

(38) Yao, Z.; Kim, S.; Aykol, M.; Li, Q.; Wu, J.; He, J.; Wolverton, C. Revealing the Conversion Mechanism of Transition Metal Oxide Electrodes during Lithiation from First-Principles. Chem. Mater. 2017, 29 (21), 9011-9022.

(39) Zhan, C.; Yao, Z.; Lu, J.; Ma, L.; Maroni, V. A.; Li, L.; Lee, E.; Alp, E. E.; Wu, T.; Wen, J.; et al. Enabling the High Capacity of Lithium-Rich Anti-Fluorite Lithium Iron Oxide by Simultaneous Anionic and Cationic Redox. Nat. Energy 2017, 2 (12), 963-971.

Li, Q.; Liu, H.; Yao, Z.; Cheng, J.; Li, T.; Li, Y.; Wolverton, C.; Wu, J.; Dravid, V. P. Electrochemistry of Selenium with Sodium and Lithium: Kinetics and Reaction Mechanism. ACS Nano 2016, 10 (9), 8788-8795.

(41) Urban, A.; Seo, D.-H.; Ceder, G. Computational Understanding of Li-Ion Batteries. npj Comput. Mater. 2016, 2 (1), 16002-16014. 
(42) Morgan, D.; Van der Ven, A.; Ceder, G. Li Conductivity in LixMPO4 (M = Mn, Fe, Co, Ni) Olivine Materials. Electrochem. Solid-State Lett. 2004, 7 (2), A30-A32.

(43) Yao, Z.; Kim, S.; Michel, K.; Zhang, Y.; Aykol, M.; Wolverton, C. Stability and Conductivity of Cation and Anion Substituted LiBH4-Based Solid-State Electrolytes. Phys. Rev. Mater. 2018, 2 (6), 065402-065408.

(44) Yu, H.-C.; Ling, C.; Bhattacharya, J.; Thomas, J. C.; Thornton, K.; Van der Ven, A. Designing the next Generation High Capacity Battery Electrodes. Energy Environ. Sci. 2014, 7 (5), 1760-1768.

(45) Rong, Z.; Malik, R.; Canepa, P.; Sai Gautam, G.; Liu, M.; Jain, A.; Persson, K.; Ceder, G. Materials Design Rules for Multivalent Ion Mobility in Intercalation Structures. Chem. Mater. 2015, 27 (17), 6016-6021.

(46) Jain, A.; Hautier, G.; Moore, C. J.; Ping Ong, S.; Fischer, C. C.; Mueller, T.; Persson, K. A.; Ceder, G. A High-Throughput Infrastructure for Density Functional Theory Calculations. Comput. Mater. Sci. 2011, 50 (8), 2295-2310.

(47) Yao, Z.; Kim, S.; He, J.; Hegde, V. I.; Wolverton, C. Interplay of Cation and Anion Redox in Li4Mn2O5 Cathode Material and Prediction of Improved Li4(Mn,M)2O5 Electrodes for Li-Ion Batteries. Sci. Adv. 2018, 4 (5), eaao6754.

(48) Curtarolo, S.; Hart, G. L. W.; Nardelli, M. B.; Mingo, N.; Sanvito, S.; Levy, O. The HighThroughput Highway to Computational Materials Design. Nat. Mater. 2013, 12 (3), 191201.

(49) Amsler, M.; Yao, Z.; Wolverton, C. Cubine, a Quasi Two-Dimensional Copper-Bismuth Nanosheet. Chem. Mater. 2017, 29 (22), 9819-9828.

(50) Kresse, G.; Hafner, J. Ab Initio Molecular Dynamics for Liquid Metals. Phys. Rev. B 
1993, $47,558-561$.

(51) Kresse, G.; Hafner, J. Ab Initio Molecular-Dynamics Simulation of the Liquid-MetalAmorphous-Semiconductor Transition in Germanium. Phys. Rev. B 1994, 49 (20), 1425114269.

(52) Kresse, G.; Furthmüller, J. Efficiency of Ab-Initio Total Energy Calculations for Metals and Semiconductors Using a Plane-Wave Basis Set. Comput. Mater. Sci. 1996, 6, 15-50.

(53) Kresse, G. Efficient Iterative Schemes for Ab Initio Total-Energy Calculations Using a Plane-Wave Basis Set. Phys. Rev. B 1996, 54 (16), 11169-11186.

(54) Blöchl, P. E. Projector Augmented-Wave Method. Phys. Rev. B 1994, 50 (24), 1795317979.

(55) Perdew, J. P.; Ernzerhof, M.; Burke, K. Rationale for Mixing Exact Exchange with Density Functional Approximations. J. Chem. Phys. 1996, 105 (22), 9982-9985.

(56) Kirklin, S.; Saal, J. E.; Meredig, B.; Thompson, A.; Doak, J. W.; Aykol, M.; Rühl, S.; Wolverton, C. The Open Quantum Materials Database (OQMD): Assessing the Accuracy of DFT Formation Energies. npj Comput. Mater. 2015, 1, 15010-15024.

(57) Saal, J. E.; Kirklin, S.; Aykol, M.; Meredig, B.; Wolverton, C. Materials Design and Discovery with High-Throughput Density Functional Theory: The Open Quantum Materials Database (OQMD). JOM 2013, 65 (11), 1501-1509.

(58) Aydinol, M. K.; Kohan, A. F.; Ceder, G.; Cho, K.; Joannopoulos, J. Ab Initio Study of Lithium Intercalation in Metal Oxides and Metal Dichalcogenides. Phys. Rev. B 1997, 56 (3), 1354-1365.

(59) Wolverton, C.; Zunger, A. First-Principles Prediction of Vacancy Order-Disorder and Intercalation Battery Voltages in LixCoO2. Phys. Rev. Lett. 1998, 81 (3), 606-609. 
(60) Liu, H.; Li, Q.; Yao, Z.; Li, L.; Li, Y.; Wolverton, C.; Hersam, M. C.; Dravid, V. P. Origin of Fracture-Resistance to Large Volume Change in Cu-Substituted Co3O4 Electrodes. Adv. Mater. 2017, 30 (4), 1704851-1704858.

(61) Li, Q.; Wu, J.; Yao, Z.; Thackeray, M. M.; Wolverton, C.; Dravid, V. P. Dynamic Imaging of Metastable Reaction Pathways in Lithiated Metal Oxide Electrodes. Nano Energy 2017, 44, 15-22.

(62) Belsky, A.; Hellenbrandt, M.; Karen, V. L.; Luksch, P. New Developments in the Inorganic Crystal Structure Database (ICSD): Accessibility in Support of Materials Research and Design. Acta Crystallogr. Sect. B Struct. Sci. 2002, 58 (3), 364-369.

(63) Beaulieu, L. Y.; Eberman, K. W.; Turner, R. L.; Krause, L. J.; Dahn, J. R. Colossal Reversible Volume Changes in Lithium Alloys. Electrochem. Solid-State Lett. 2001, 4 (9), A137-A140.

(64) Guminski, C. The Ca-Hg (Calcium-Mercury) System. J. Phase Equilibria 1993, 14 (1), 90-96.

\section{Acknowledgement}

Funding: Z.Y. (Conceived the idea, DFT calculations, and analysis of results) and A.A.-G. (leadership of project) were supported as part of the Nanoporous Materials Genome Center by the U.S. Department of Energy, Office of Science, Office of Basic Energy Sciences under award number DE-SC0008688. C.W. (leadership of project) was supported as part of the Center for Electrochemical Energy Science (CEES), an Energy Frontier Research Center funded by the U.S. Department of Energy, Office of the Science, Basic Energy Science under the award number DEAC02-06CH11357. V.I.H. (high-throughput workflows) acknowledges support from the Center 
for Hierarchical Materials Design (CHiMaD) and from the U.S. Department of Commerce, National Institute of Standards and Technology under award no. 70NANB14H012. We gratefully acknowledge the computing resources from: 1) the National Energy Research Scientific Computing Center, a DOE Office of Science User Facility supported by the Office of Science of the U.S. Department of Energy under Contract DE-AC02-05CH11231. 2) Blues, a highperformance computing cluster operated by the Laboratory Computing Resource Center at Argonne National Laboratory. Author contributions: Z.Y. conceived the overall project and DFT calculation of ground state structure prediction, structural pathway, voltage and energy density. C.W. provided overall direction and advice for project, and analyzed the results. V.I.H. performed high-throughput calculation of doping options. A.A-G. provided feedback for the project. Competing interests: All authors declare that they have no competing interests. Data and materials availability: All data needed to evaluate the conclusions in the paper are present in the paper and/or the Supplementary Materials. Additional data related to this paper may be requested from the authors. 


\section{Figures}
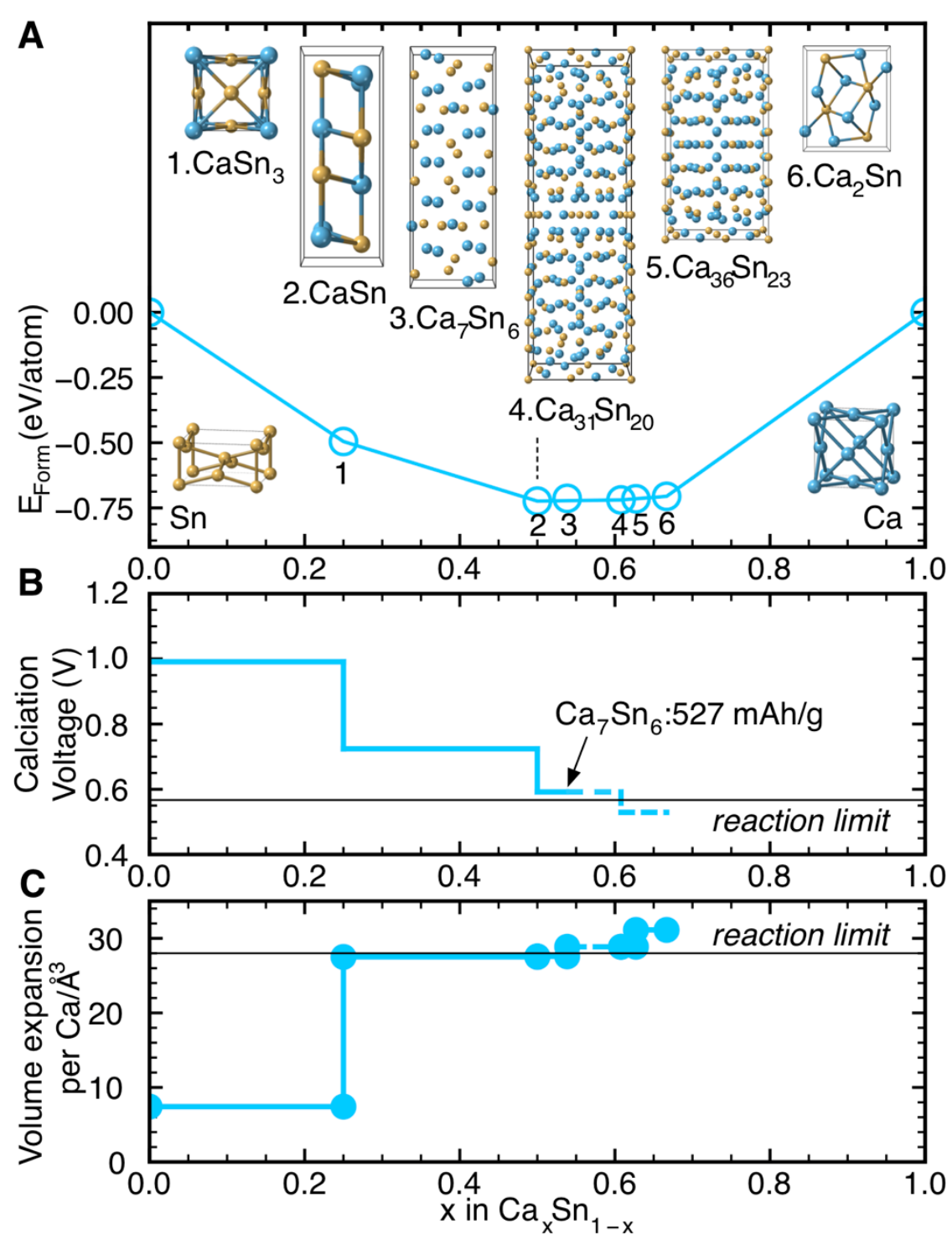

Figure 1. Electrochemical calciation process of Sn. (A) Sn-Ca convex hull with all the known

Sn-Ca intermetallic compounds predicted to be on or slightly $(<10 \mathrm{meV} /$ atom $)$ above the convex hull. Structures for Sn, Ca, and all the intermetallic compound are shown in the insets. (B) Corresponding calciation voltage profile during the calciation process of Sn. Experimentally observed calciation ends at $\mathrm{Ca}_{7} \mathrm{Sn}_{6}$ before the calciation voltage profile reaching the last plateau of $0.53 \mathrm{~V},{ }^{14}$ which can be seen as the threshold voltage of calciation. (C) Calculated volume expansion per $\mathrm{Ca}$ as a function of calciation. 

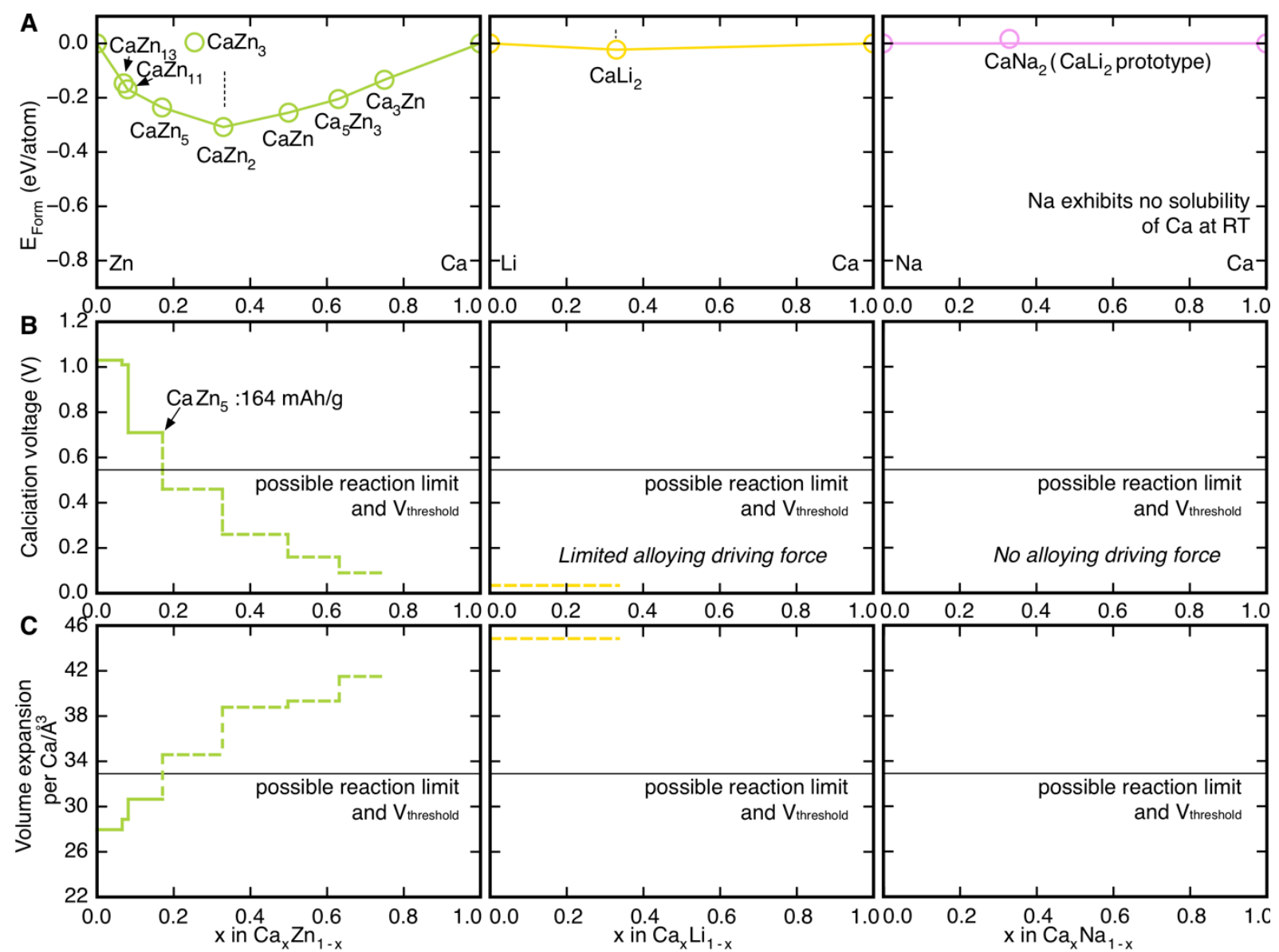

Figure 2. Electrochemical calciation processes of $\mathrm{Zn}, \mathrm{Li}, \mathrm{Na}$ and the determination of $\mathrm{M}-\mathrm{Ca}$

alloy anode calciation threshold voltage. (A) $\mathrm{Zn}-\mathrm{Ca}, \mathrm{Li}-\mathrm{Ca}, \mathrm{Na}-\mathrm{Ca}$ convex hulls. (B)

Corresponding calciation voltage profiles during the calciation of $\mathrm{Zn}$ and $\mathrm{Li}$. (C) Calculated volume expansions per Ca upon calciations of $\mathrm{Zn}$ and $\mathrm{Li}$. Compare with the Sn-Ca convex hull, the bottom of the $\mathrm{Zn}-\mathrm{Ca}$ convex hull deviated to the $\mathrm{Zn}$ side with rapidly decreased formation energy in a small Ca concentration range indicating a fast calciation voltage declining and losing of reaction driving force. Similarly, the extremely shallow feature of the Li-Ca convex hull implying a low calciation voltage and inadequate reaction driving force, validating the observed significantly limited calciation capacity of $\mathrm{Zn}$ and Li. ${ }^{14}$ No stable intermetallic compound is identified for the $\mathrm{Na}-\mathrm{Ca}$ convex hull, reflecting the fact of no solubility of $\mathrm{Ca}$ in $\mathrm{Na}$. 


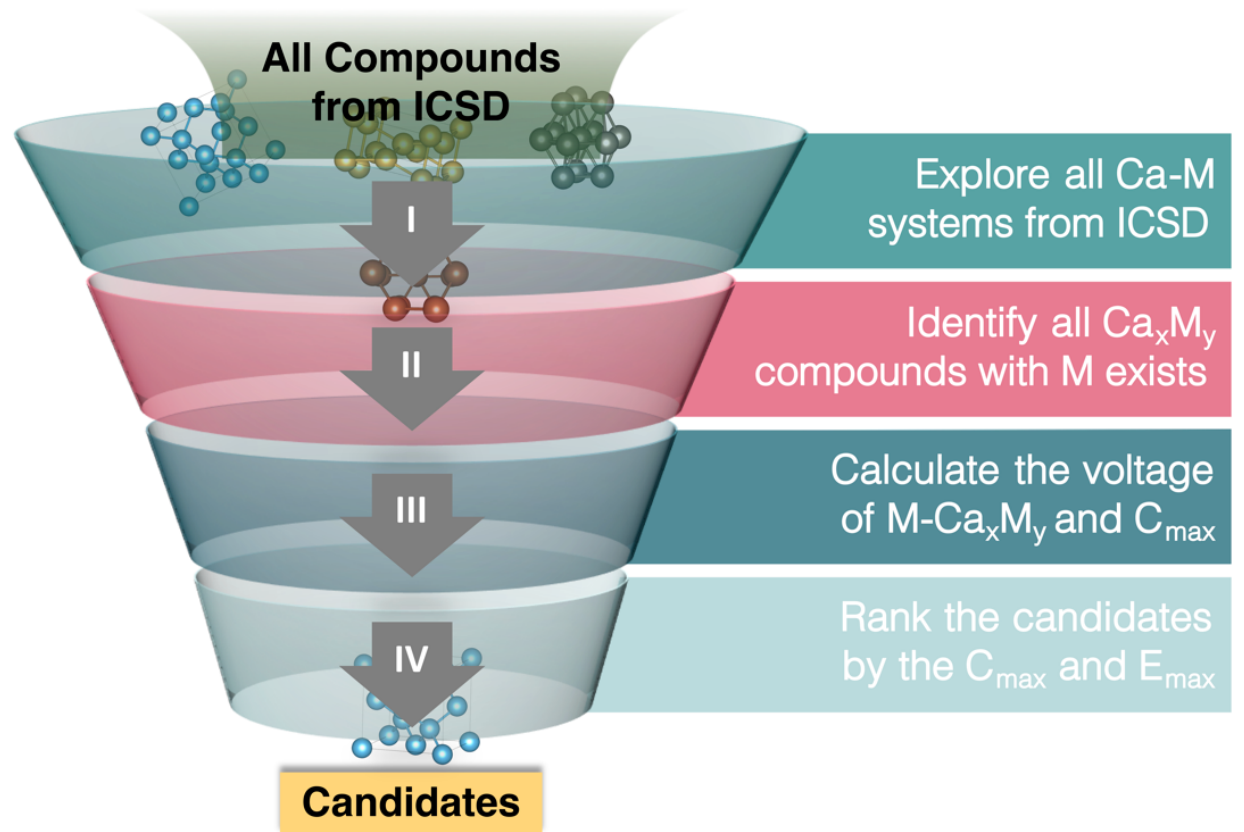

Figure 3. Screening strategy for the search of calcium-metal alloy anodes. We proceeded the high-throughput screening following a four-step strategy. Started with all the compounds in the Inorganic Crystal Structure Database (ICSD), we identify the M-Ca alloys for which the M also exists in the ICSD with M can be metal elements and other alloys. Then we calculate the reaction voltage profiles for each $\mathrm{M}-\mathrm{Ca}$ system and determine its maximum capacity $\mathrm{C}_{\max }$. Lastly, we evaluate the energy densities $E_{\max }$ corresponding to $\mathrm{C}_{\max }$ of all the systems using their output voltage, rank them based on their $\mathrm{E}_{\max }$ values, and select the ones with highest energy densities as our top candidates. 


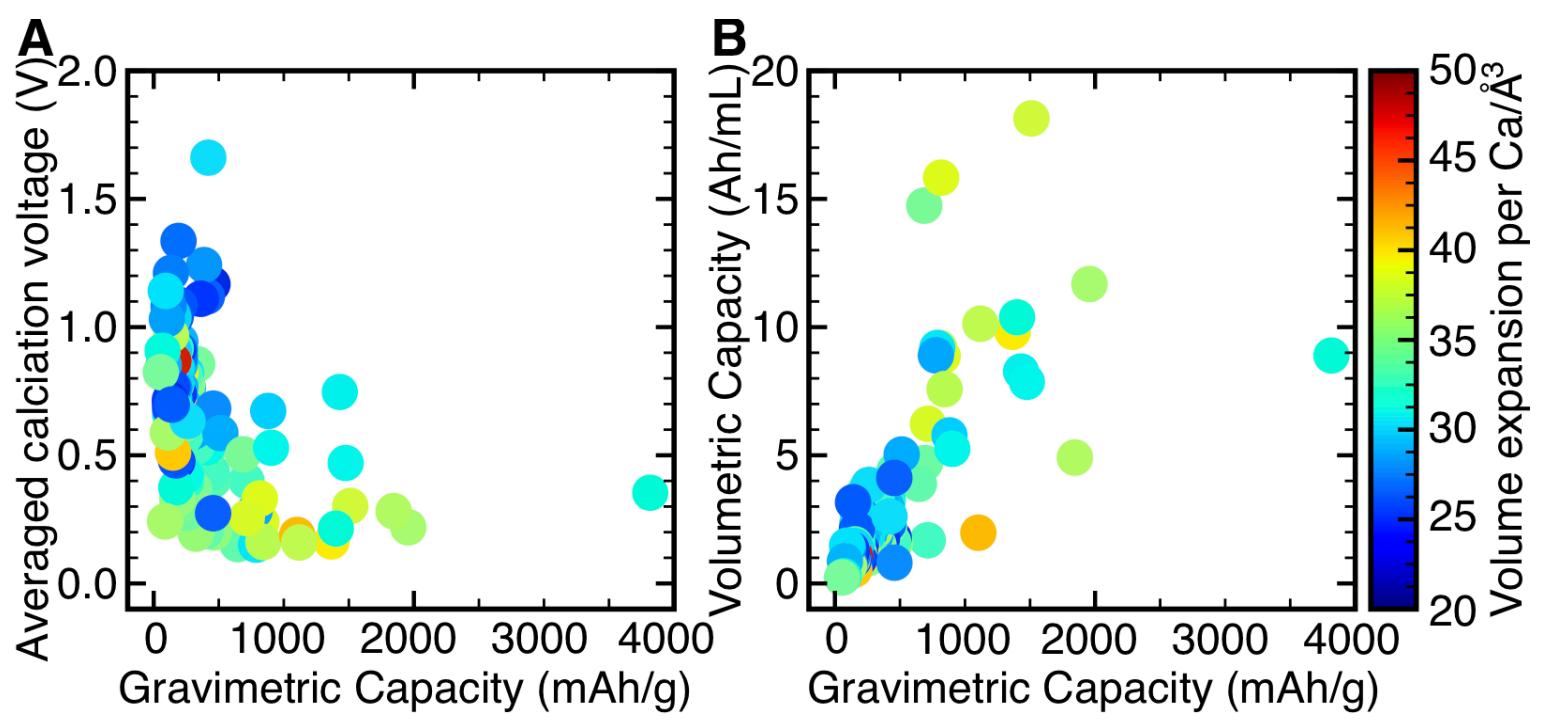

Figure 4. Summary of the identified M-Ca systems and corresponding properties. (A) Averaged calciation voltages and gravimetric capacities and (B) Volumetric capacities of all the $115 \mathrm{M}$-Ca systems. The color of each marker indicates the volume expansion per Ca corresponding to the final product of specific M-Ca system. 


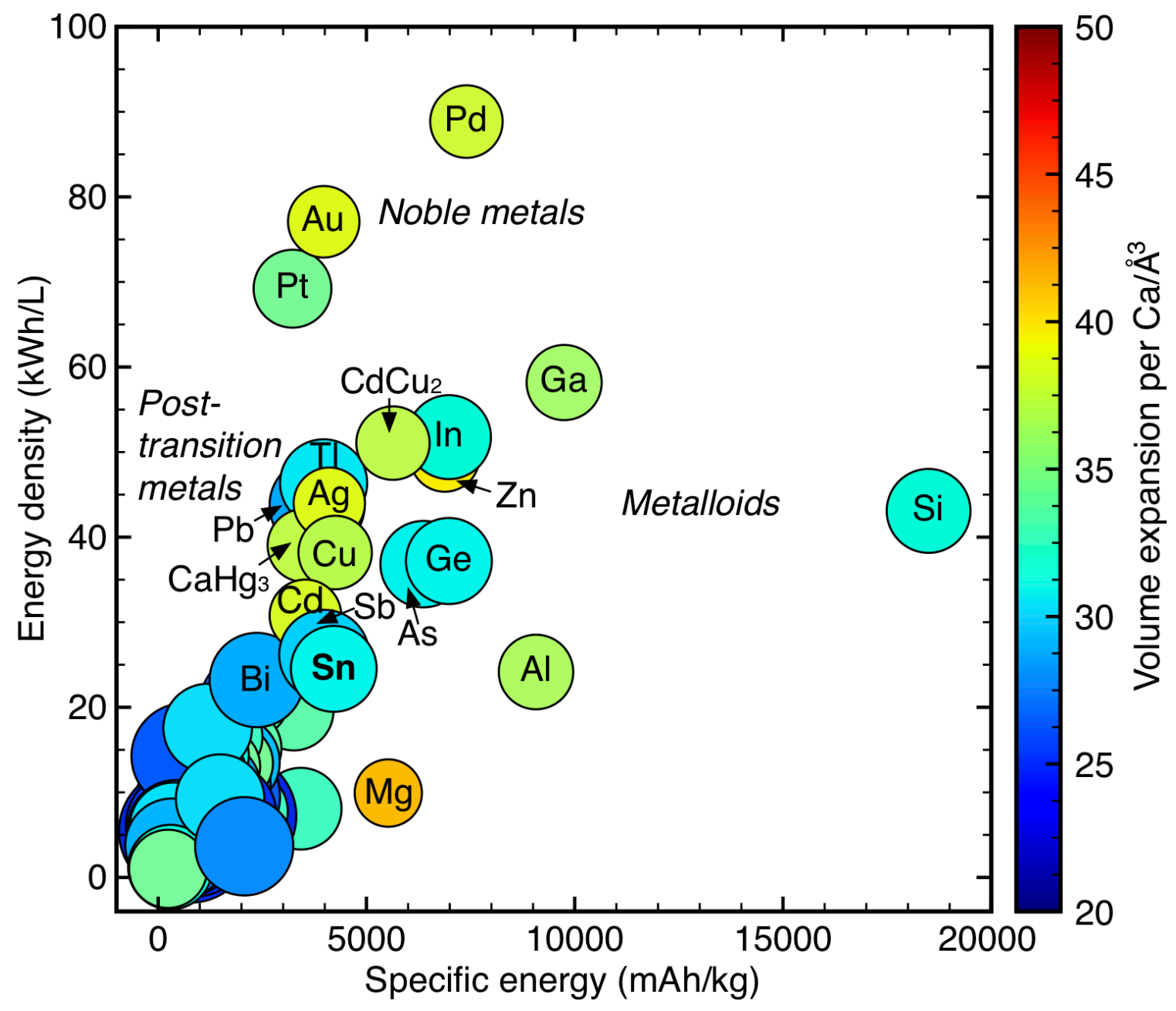

Figure 5. HT-DFT screening results for high performance M-Ca anodes with relaxed voltage

constraint. We performed computational screening for $\mathrm{M}-\mathrm{Ca}$ alloy-type anode materials. Candidates are systems with energy densities and specific energies (calculated with graphite cathode usage assumed as discussed in Section 2.4) higher than the counterparts of Sn. The color (and size) of each marker indicates the volume expansion (inversed trend for size) per Ca. Our top candidates are metalloids ( $\mathrm{Si}, \mathrm{Ge}, \mathrm{As}, \mathrm{Sb}$ ), post-transition metals (Ga, Al, In, Tl, Pb, Hg, Cd), transition metals $\left(\mathrm{Cu}, \mathrm{CdCu}_{2}\right)$, and noble metals $(\mathrm{Pd}, \mathrm{Au}, \mathrm{Pt}, \mathrm{Ag})$. 


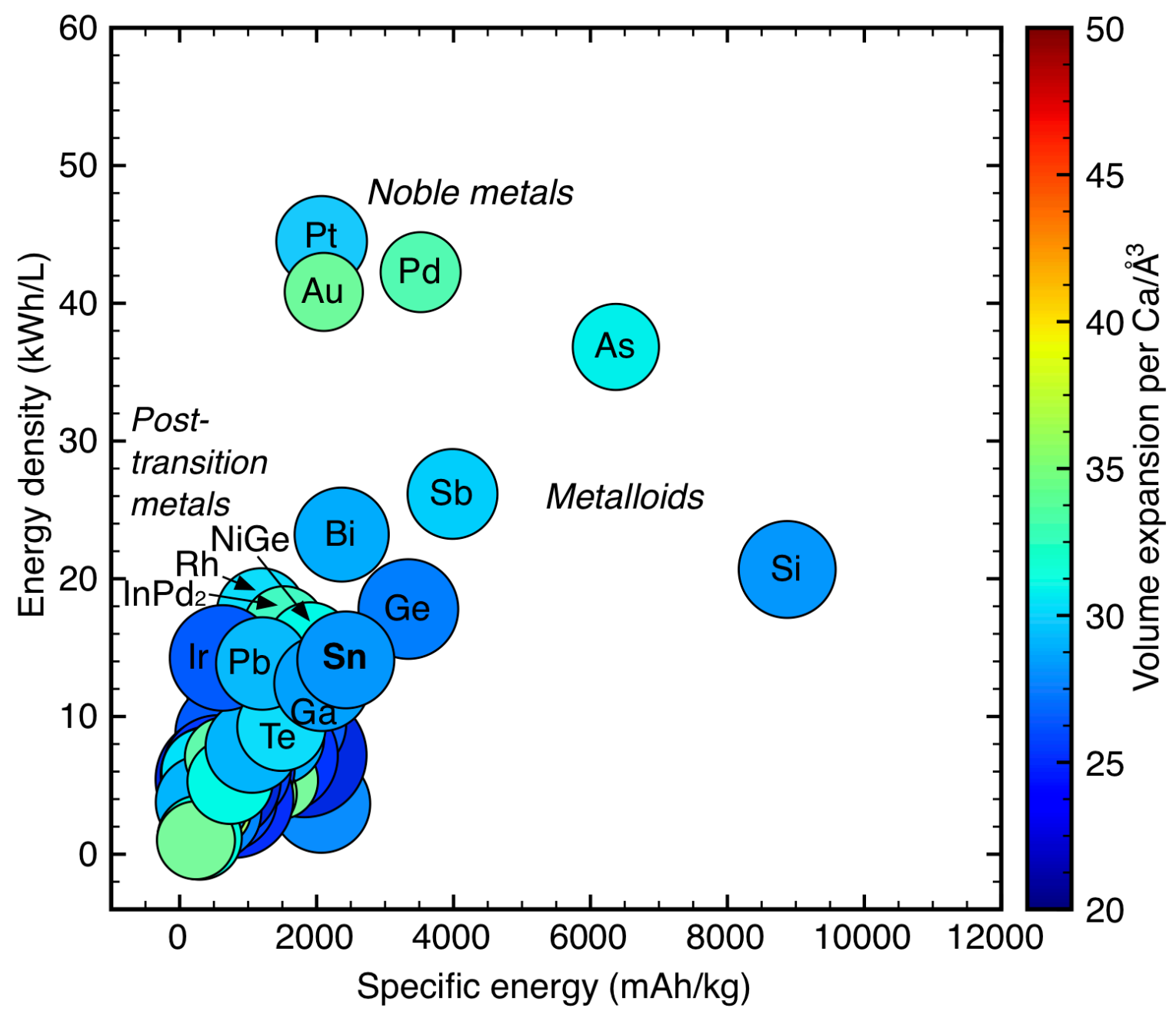

Figure 6. HT-DFT screening results for high performance M-Ca anodes with restrictive voltage constraint. We performed computational screening for M-Ca alloy-type anode materials. Candidates are systems with energy densities and specific energies (calculated with graphite cathode usage assumed as discussed in Section 2.4) higher than the counterparts of Sn. The color (and size) of each marker indicates the volume expansion (inversed trend for size) per Ca. Our top candidates are metalloids ( $\mathrm{Si}, \mathrm{As}, \mathrm{Sb}, \mathrm{Ge})$, post-transition metals (Bi), and noble metals (Pt, Pd, $\mathrm{Au})$. 
Table 1. Candidates for high performance M-Ca alloy-type anodes with relaxed voltage constraint $\left(V_{\text {threshold }}=\mathbf{0 . 1 V}\right)$. For each candidate system we show the reactant, final product, averaged voltage, gravimetric capacity, volumetric capacity, energy density, specific energy, and volume expansion maximum.

\begin{tabular}{|c|c|c|c|c|c|c|}
\hline Candidates and reactions & $\begin{array}{c}\text { Averaged } \\
\text { calciation } \\
\text { voltage (V) }\end{array}$ & $\begin{array}{c}\text { Gravimetric } \\
\text { Capacity } \\
(\mathrm{mAh} / \mathrm{g})\end{array}$ & $\begin{array}{l}\text { Volumetric } \\
\text { Capacity } \\
(\mathrm{mAh} / \mathrm{mL})\end{array}$ & $\begin{array}{l}\text { Energy } \\
\text { Density } \\
(\mathrm{Wh} / \mathrm{L})\end{array}$ & $\begin{array}{c}\text { Specific } \\
\text { Energy } \\
(\mathrm{Wh} / \mathrm{kg})\end{array}$ & $\begin{array}{c}\text { Volume } \\
\text { Expansion } \\
\text { per } \mathrm{Ca} / \AA^{3}\end{array}$ \\
\hline $\mathrm{Si}+2 \mathrm{Ca} \rightarrow \mathrm{Ca}_{2} \mathrm{Si}$ & 0.35 & 3817 & 8892 & 43089 & 18495 & 31.89 \\
\hline $\mathrm{Ga}+28 / 11 \mathrm{Ca} \rightarrow 1 / 11 \mathrm{Ca}_{28} \mathrm{Ga}_{11}$ & 0.22 & 1957 & 11680 & 58178 & 9746 & 36.12 \\
\hline $\mathrm{Al}+13 / 14 \mathrm{Ca} \rightarrow 1 / 14 \mathrm{Ca}_{13} \mathrm{Al}_{14}$ & 0.28 & 1845 & 4910 & 24149 & 9071 & 36.47 \\
\hline $\mathrm{Pd}+3 \mathrm{Ca} \rightarrow \mathrm{Ca}_{3} \mathrm{Pd}$ & 0.30 & 1511 & 18141 & 88853 & 7400 & 37.75 \\
\hline $\mathrm{In}+3 \mathrm{Ca} \rightarrow \mathrm{Ca}_{3} \mathrm{In}$ & 0.21 & 1400 & 10381 & 51759 & 6982 & 31.89 \\
\hline $\mathrm{Ge}+2 \mathrm{Ca} \rightarrow \mathrm{Ca}_{2} \mathrm{Ge}$ & 0.47 & 1476 & 7864 & 37195 & 6980 & 31.06 \\
\hline $\mathrm{Zn}+5 / 3 \mathrm{Ca} \rightarrow 1 / 3 \mathrm{Ca}_{5} \mathrm{Zn}_{3}$ & 0.16 & 1366 & 9816 & 49435 & 6881 & 39.78 \\
\hline $\mathrm{As}+2 \mathrm{Ca} \rightarrow \mathrm{Ca}_{2} \mathrm{As}$ & 0.75 & 1431 & 8271 & 36830 & 6371 & 30.93 \\
\hline $\mathrm{CdCu}_{2}+5 \mathrm{Ca} \rightarrow \mathrm{Ca}_{5} \mathrm{CdCu}_{2}$ & 0.16 & 1119 & 10130 & 51056 & 5637 & 37.14 \\
\hline $\mathrm{Cu}+\mathrm{Ca} \rightarrow \mathrm{CaCu}$ & 0.16 & 843 & 7581 & 38192 & 4249 & 37.10 \\
\hline $\mathrm{Ag}+5 / 3 \mathrm{Ca} \rightarrow 1 / 3 \mathrm{Ca}_{5} \mathrm{Ag}_{3}$ & 0.24 & 828 & 8866 & 43982 & 4108 & 38.47 \\
\hline $\mathrm{Sb}+2 \mathrm{Ca} \rightarrow \mathrm{Ca}_{2} \mathrm{Sb}$ & 0.67 & 880 & 5778 & 26156 & 3985 & 29.66 \\
\hline $\mathrm{Au}+3 \mathrm{Ca} \rightarrow \mathrm{Ca}_{3} \mathrm{Au}$ & 0.33 & 816 & 15830 & 77078 & 3975 & 38.42 \\
\hline $\mathrm{Tl}+3 \mathrm{Ca} \rightarrow \mathrm{Ca}_{3} \mathrm{Tl}$ & 0.15 & 787 & 9185 & 46373 & 3972 & 30.62 \\
\hline $\mathrm{Pb}+3 \mathrm{Ca} \rightarrow \mathrm{Ca}_{3} \mathrm{~Pb}$ & 0.28 & 776 & 8897 & 43744 & 3816 & 28.10 \\
\hline $\mathrm{Cd}+3 / 2 \mathrm{Ca} \rightarrow 1 / 2 \mathrm{Ca}_{3} \mathrm{Cd}_{2}$ & 0.26 & 715 & 6227 & 30788 & 3536 & 38.22 \\
\hline $\mathrm{Pt}+5 / 2 \mathrm{Ca} \rightarrow 1 / 2 \mathrm{Ca}_{5} \mathrm{Pt}_{2}$ & 0.50 & 687 & 14738 & 69208 & 3225 & 34.62 \\
\hline $1 / 3 \mathrm{CaHg}_{3}+8 / 3 \mathrm{Ca} \rightarrow \mathrm{Ca}_{3} \mathrm{Hg}$ & 0.12 & 668 & 7662 & 38923 & 3392 & 37.25 \\
\hline $\mathrm{Sn}+2 \mathrm{Ca} \rightarrow \mathrm{Ca}_{2} \mathrm{Sn}$ & 0.53 & 903 & 5249 & 24515 & 4216 & 31.13 \\
\hline
\end{tabular}


Table 2. Candidates for high performance M-Ca alloy-type anodes with restrictive voltage constraint $\left(\mathrm{V}_{\text {threshold }}=\mathbf{0 . 5 3} \mathrm{V}\right)$. For each candidate system we show the reactant, final product, averaged voltage, gravimetric capacity, volumetric capacity, energy density, specific energy, and volume expansion maximum.

\begin{tabular}{l|cccccc}
\hline \multicolumn{1}{c|}{ Candidates and reactions } & $\begin{array}{c}\text { Averaged } \\
\text { calciation } \\
\text { voltage }(\mathrm{V})\end{array}$ & $\begin{array}{c}\text { Gravimetric } \\
\text { Capacity } \\
(\mathrm{mAh} / \mathrm{g})\end{array}$ & $\begin{array}{c}\text { Volumetric } \\
\text { Capacity } \\
(\mathrm{mAh} / \mathrm{mL})\end{array}$ & $\begin{array}{c}\text { Energy } \\
\text { Density } \\
(\mathrm{Wh} / \mathrm{L})\end{array}$ & $\begin{array}{c}\text { Specific } \\
\text { Energy } \\
(\mathrm{Wh} / \mathrm{kg})\end{array}$ & $\begin{array}{c}\text { Volume } \\
\text { Expansion } \\
\text { per } \mathrm{Ca} / \AA^{3}\end{array}$ \\
\hline $\mathrm{Si}+\mathrm{Ca} \rightarrow \mathrm{CaSi}$ & 0.55 & 1908 & 4446 & 20673 & 8874 & 27.60 \\
\hline $\mathrm{As}+2 \mathrm{Ca} \rightarrow \mathrm{Ca}{ }_{2} \mathrm{As}$ & 0.75 & 1431 & 8271 & 36830 & 6371 & 30.93 \\
\hline $\mathrm{Sb}+2 \mathrm{Ca} \rightarrow \mathrm{Ca}_{2} \mathrm{Sb}$ & 0.67 & 880 & 5778 & 26156 & 3985 & 29.66 \\
\hline $\mathrm{Pd}+3 / 2 \mathrm{Ca} \rightarrow 1 / 2 \mathrm{Ca}_{3} \mathrm{Pd}_{2}$ & 0.54 & 755 & 9070 & 42259 & 3520 & 33.50 \\
\hline $\mathrm{Ge}+\mathrm{Ca} \rightarrow \mathrm{CaGe}$ & 0.67 & 738 & 3932 & 17799 & 3340 & 26.90 \\
\hline $\mathrm{Bi}+2 \mathrm{Ca} \rightarrow \mathrm{Ca} \mathrm{Bi}$ & 0.59 & 513 & 5031 & 23206 & 2366 & 28.37 \\
\hline $\mathrm{Pt}+5 / 3 \mathrm{Ca} \rightarrow 1 / 3 \mathrm{Ca}_{5} \mathrm{Pt}_{3}$ & 0.67 & 458 & 9825 & 44498 & 2074 & 29.40 \\
\hline $\mathrm{Au}+5 / 3 \mathrm{Ca} \rightarrow 1 / 3 \mathrm{Ca}_{5} \mathrm{Au}_{3}$ & 0.56 & 454 & 8795 & 40824 & 2105 & 34.41 \\
\hline $\mathbf{S n}+\mathbf{7 / 6 C a} \rightarrow \mathbf{1 / 6 C a _ { 7 }} \mathbf{S n}_{\mathbf{6}}$ & $\mathbf{0 . 5 9}$ & $\mathbf{5 2 7}$ & $\mathbf{3 0 6 2}$ & $\mathbf{1 4 1 0 9}$ & $\mathbf{2 4 2 6}$ & $\mathbf{2 7 . 5 9}$ \\
\hline
\end{tabular}




\title{
Supplementary Materials for
}

\section{Discovery of calcium-metal alloy anodes for reversible Ca-ion batteries}

\author{
Zhenpeng Yao, ${ }^{12}$ Vinay I. Hegde, ${ }^{2}$ Alán Aspuru-Guzik, ${ }^{1345^{*}}$ Chris Wolverton ${ }^{2 *}$ \\ ${ }^{1}$ Department of Chemistry and Chemical Biology, Harvard University, 12 Oxford Street, \\ Cambridge, Massachusetts 02138, United States \\ ${ }^{2}$ Department of Materials Science and Engineering, Northwestern University, 2220 Campus \\ Drive, Evanston, Illinois 60208, United States \\ ${ }^{3}$ Department of Chemistry and Department of Computer Science, University of Toronto, Toronto, \\ Ontario M5S 3H6, Canada \\ ${ }^{4}$ Vector Institute for Artificial Intelligence, Toronto, Ontario M5S 1M1, Canada \\ ${ }^{5}$ Canadian Institute for Advanced Research (CIFAR) Senior Fellow, Toronto, Ontario M5S 1M1, \\ Canada \\ *Correspondence: alan@aspuru.com*Correspondence: c-wolverton@northwestern.edu
}

\section{Table of Contents}

Supplementary Table S1

Supplementary Table S2

Supplementary Table S3

Supplementary Table S4
2

5

7

10 
Table S1. Full reaction pathways for candidates with relaxed voltage constraint $\left(\mathrm{V}_{\text {threshold }}=\right.$

0.1V). For each reaction of specific candidate system, we show the reactant, product, voltage, gravimetric capacity, volumetric capacity, energy density, specific energy, and volume expansion.

\begin{tabular}{|c|c|c|c|c|c|c|}
\hline Candidates and reactions & $\begin{array}{l}\text { Calciation } \\
\text { voltages } \\
\text { (V) }\end{array}$ & $\begin{array}{c}\text { Gravimetric } \\
\text { Capacity } \\
(\mathrm{mAh} / \mathrm{g})\end{array}$ & $\begin{array}{c}\text { Volumetric } \\
\text { Capacity } \\
(\mathrm{mAh} / \mathrm{mL})\end{array}$ & $\begin{array}{l}\text { Energy } \\
\text { Density } \\
(\mathrm{Wh} / \mathrm{L})\end{array}$ & $\begin{array}{l}\text { Specific } \\
\text { Energy } \\
(\mathrm{Wh} / \mathrm{kg})\end{array}$ & $\begin{array}{c}\text { Volume } \\
\text { Expansion } \\
\text { per } \mathrm{Ca} / \AA^{3}\end{array}$ \\
\hline $\mathrm{Si}+1 / 2 \mathrm{Ca} \rightarrow 1 / 2 \mathrm{CaSi}_{2}$ & 0.58 & 954 & 2223 & 10261 & 4404 & 27.29 \\
\hline $\mathrm{Si}+14 / 19 \mathrm{Ca} \rightarrow 1 / 19 \mathrm{Ca}_{14} \mathrm{Si}_{19}$ & 0.56 & 1406 & 3276 & 15193 & 6522 & 26.04 \\
\hline $\mathrm{Si}+\mathrm{Ca} \rightarrow \mathrm{CaSi}$ & 0.55 & 1908 & 4446 & 20673 & 8874 & 27.60 \\
\hline $\mathrm{Si}+5 / 3 \mathrm{Ca} \rightarrow 1 / 3 \mathrm{Ca}_{5} \mathrm{Si}_{3}$ & 0.40 & 3181 & 7410 & 35581 & 15273 & 52.32 \\
\hline $\mathrm{Si}+2 \mathrm{Ca} \rightarrow \mathrm{Ca}_{2} \mathrm{Si}$ & 0.35 & 3817 & 8892 & 43089 & 18495 & 31.89 \\
\hline $\mathrm{Ga}+1 / 4 \mathrm{Ca} \rightarrow 1 / 4 \mathrm{CaGa}_{4}$ & 0.91 & 192 & 1147 & 4919 & 824 & 23.57 \\
\hline $\mathrm{Ga}+3 / 8 \mathrm{Ca} \rightarrow 1 / 8 \mathrm{Ca}_{3} \mathrm{Ga}_{8}$ & 0.83 & 288 & 1720 & 7520 & 1260 & 28.77 \\
\hline $\mathrm{Ga}+1 / 2 \mathrm{Ca} \rightarrow 1 / 2 \mathrm{CaGa}_{2}$ & 0.79 & 384 & 2294 & 10118 & 1695 & 24.71 \\
\hline $\mathrm{Ga}+3 / 5 \mathrm{Ca} \rightarrow 1 / 5 \mathrm{Ca}_{3} \mathrm{Ga}_{5}$ & 0.70 & 461 & 2753 & 12403 & 2078 & 28.02 \\
\hline $\mathrm{Ga}+1 \mathrm{Ca} \rightarrow \mathrm{CaGa}$ & 0.48 & 769 & 4589 & 21668 & 3630 & 33.22 \\
\hline $\mathrm{Ga}+11 / 7 \mathrm{Ca} \rightarrow 1 / 7 \mathrm{Ca}_{11} \mathrm{Ga}_{7}$ & 0.33 & 1208 & 7211 & 35145 & 5888 & 35.16 \\
\hline $\mathrm{Ga}+5 / 3 \mathrm{Ca} \rightarrow 1 / 3 \mathrm{Ca}_{5} \mathrm{Ga}_{3}$ & 0.31 & 1281 & 7648 & 37397 & 6265 & 36.08 \\
\hline $\mathrm{Ga}+28 / 11 \mathrm{Ca} \rightarrow 1 / 11 \mathrm{Ca}_{28} \mathrm{Ga}_{11}$ & 0.22 & 1957 & 11680 & 58178 & 9746 & 36.12 \\
\hline $\mathrm{Al}+1 / 4 \mathrm{Ca} \rightarrow 1 / 4 \mathrm{CaAl}_{4}$ & 0.50 & 497 & 1322 & 6211 & 2333 & 37.42 \\
\hline $\mathrm{Al}+1 / 2 \mathrm{Ca} \rightarrow 1 / 2 \mathrm{CaAl}_{2}$ & 0.50 & 993 & 2644 & 12422 & 4666 & 31.34 \\
\hline $\mathrm{Al}+13 / 14 \mathrm{Ca} \rightarrow 1 / 14 \mathrm{Ca}_{13} \mathrm{Al}_{14}$ & 0.28 & 1845 & 4910 & 24149 & 9071 & 36.47 \\
\hline $\mathrm{Pd}+1 / 5 \mathrm{Ca} \rightarrow 1 / 5 \mathrm{CaPd}_{5}$ & 1.12 & 101 & 1209 & 4938 & 411 & 23.32 \\
\hline $\mathrm{Pd}+1 / 2 \mathrm{Ca} \rightarrow 1 / 2 \mathrm{CaPd}_{2}$ & 1.07 & 252 & 3023 & 12490 & 1040 & 26.86 \\
\hline $\mathrm{Pd}+1 \mathrm{Ca} \rightarrow \mathrm{CaPd}$ & 0.69 & 504 & 6047 & 27284 & 2272 & 28.82 \\
\hline $\mathrm{Pd}+3 / 2 \mathrm{Ca} \rightarrow 1 / 2 \mathrm{Ca}_{3} \mathrm{Pd}_{2}$ & 0.54 & 755 & 9070 & 42259 & 3520 & 33.50 \\
\hline $\mathrm{Pd}+5 / 2 \mathrm{Ca} \rightarrow 1 / 2 \mathrm{Ca}_{5} \mathrm{Pd}_{2}$ & 0.36 & 1259 & 15117 & 73197 & 6096 & 36.90 \\
\hline$\underline{\mathrm{Pd}+3 \mathrm{Ca} \rightarrow \mathrm{Ca}_{3} \mathrm{Pd}}$ & 0.30 & 1511 & 18141 & 88853 & 7400 & 37.75 \\
\hline $\mathrm{In}+1 / 2 \mathrm{Ca} \rightarrow 1 / 2 \mathrm{CaIn}_{2}$ & 0.68 & 233 & 1730 & 7825 & 1056 & 28.76 \\
\hline $\mathrm{In}+1 \mathrm{Ca} \rightarrow \mathrm{CaIn}$ & 0.49 & 467 & 3460 & 16305 & 2200 & 31.31 \\
\hline $\mathrm{In}+2 \mathrm{Ca} \rightarrow \mathrm{Ca}_{2} \mathrm{In}$ & 0.29 & 934 & 6921 & 33973 & 4583 & 35.94 \\
\hline $\mathrm{In}+8 / 3 \mathrm{Ca} \rightarrow 1 / 3 \mathrm{Ca}_{8} \mathrm{In}_{3}$ & 0.24 & 1245 & 9227 & 45768 & 6174 & 36.83 \\
\hline $\mathrm{In}+3 \mathrm{Ca} \rightarrow \mathrm{Ca}_{3} \mathrm{In}$ & 0.21 & 1400 & 10381 & 51759 & 6982 & 31.89 \\
\hline $\mathrm{Ge}+1 / 2 \mathrm{Ca} \rightarrow 1 / 2 \mathrm{CaGe}_{2}$ & 0.74 & 369 & 1966 & 8764 & 1645 & 24.91 \\
\hline $\mathrm{Ge}+1 \mathrm{Ca} \rightarrow \mathrm{CaGe}$ & 0.67 & 738 & 3932 & 17799 & 3340 & 26.90 \\
\hline $\mathrm{Ge}+7 / 6 \mathrm{Ca} \rightarrow 1 / 6 \mathrm{Ca}_{7} \mathrm{Ge}_{6}$ & 0.51 & 861 & 4587 & 21504 & 4035 & 28.42 \\
\hline $\mathrm{Ge}+5 / 3 \mathrm{Ca} \rightarrow 1 / 3 \mathrm{Ca}_{5} \mathrm{Ge}_{3}$ & 0.51 & 1230 & 6553 & 30720 & 5765 & 30.72 \\
\hline $\mathrm{Ge}+2 \mathrm{Ca} \rightarrow \mathrm{Ca}_{2} \mathrm{Ge}$ & 0.47 & 1476 & 7864 & 37195 & 6980 & 31.06 \\
\hline $\mathrm{Zn}+1 / 13 \mathrm{Ca} \rightarrow 1 / 13 \mathrm{CaZn} \mathrm{n}_{13}$ & 1.03 & 63 & 453 & 1890 & 263 & 27.77 \\
\hline
\end{tabular}




\begin{tabular}{|c|c|c|c|c|c|c|}
\hline $\mathrm{Zn}+1 / 11 \mathrm{Ca} \rightarrow 1 / 11 \mathrm{CaZn} \mathrm{C}_{11}$ & 1.02 & 75 & 535 & 2241 & 312 & 28.53 \\
\hline $\mathrm{Zn}+1 / 5 \mathrm{Ca} \rightarrow 1 / 5 \mathrm{CaZn}_{5}$ & 0.71 & 164 & 1178 & 5293 & 737 & 31.26 \\
\hline $\mathrm{Zn}+1 / 2 \mathrm{Ca} \rightarrow 1 / 2 \mathrm{CaZn}_{2}$ & 0.46 & 410 & 2945 & 13950 & 1942 & 34.50 \\
\hline $\mathrm{Zn}+1 \mathrm{Ca} \rightarrow \mathrm{CaZn}$ & 0.26 & 820 & 5890 & 29125 & 4054 & 39.07 \\
\hline $\mathrm{Zn}+5 / 3 \mathrm{Ca} \rightarrow 1 / 3 \mathrm{Ca}_{5} \mathrm{Zn}_{3}$ & 0.16 & 1366 & 9816 & 49435 & 6881 & 39.78 \\
\hline $\mathrm{As}+1 / 3 \mathrm{Ca} \rightarrow 1 / 3 \mathrm{CaAs}_{3}$ & 1.14 & 238 & 1378 & 5599 & 969 & 27.41 \\
\hline $\mathrm{As}+2 / 3 \mathrm{Ca} \rightarrow 1 / 3 \mathrm{Ca}_{2} \mathrm{As}_{3}$ & 1.12 & 477 & 2757 & 11257 & 1947 & 27.25 \\
\hline $\mathrm{As}+1 \mathrm{Ca} \rightarrow \mathrm{CaAs}$ & 1.10 & 715 & 4135 & 16947 & 2932 & 31.03 \\
\hline $\mathrm{As}+5 / 3 \mathrm{Ca} \rightarrow 1 / 3 \mathrm{Ca}_{5} \mathrm{As}_{3}$ & 0.90 & 1192 & 6892 & 29665 & 5132 & 28.63 \\
\hline $\mathrm{As}+2 \mathrm{Ca} \rightarrow \mathrm{Ca}_{2} \mathrm{As}$ & 0.75 & 1431 & 8271 & 36830 & 6371 & 30.93 \\
\hline $\mathrm{CdCu}_{2}+5 \mathrm{Ca} \rightarrow \mathrm{Ca}_{5} \mathrm{CdCu}_{2}$ & 0.16 & 1119 & 10130 & 51056 & 5637 & 37.14 \\
\hline $\mathrm{Cu}+1 / 5 \mathrm{Ca} \rightarrow 1 / 5 \mathrm{CaCu}_{5}$ & 0.41 & 169 & 1516 & 7268 & 809 & 32.14 \\
\hline $\mathrm{Cu}+\mathrm{Ca} \rightarrow \mathrm{CaCu}$ & 0.16 & 843 & 7581 & 38192 & 4249 & 37.10 \\
\hline $\mathrm{Ag}+2 / 7 \mathrm{Ca} \rightarrow 1 / 7 \mathrm{Ca}_{2} \mathrm{Ag}_{7}$ & 0.56 & 142 & 1520 & 7055 & 659 & 33.60 \\
\hline $\mathrm{Ag}+3 / 8 \mathrm{Ca} \rightarrow 1 / 8 \mathrm{Ca}_{3} \mathrm{Ag}_{8}$ & 0.51 & 186 & 1995 & 9363 & 875 & 34.06 \\
\hline $\mathrm{Ag}+1 / 2 \mathrm{Ca} \rightarrow 1 / 2 \mathrm{CaAg}_{2}$ & 0.46 & 248 & 2660 & 12596 & 1177 & 35.68 \\
\hline $\mathrm{Ag}+1 \mathrm{Ca} \rightarrow \mathrm{CaAg}$ & 0.35 & 497 & 5319 & 25804 & 2410 & 37.36 \\
\hline $\mathrm{Ag}+5 / 3 \mathrm{Ca} \rightarrow 1 / 3 \mathrm{Ca}_{5} \mathrm{Ag}_{3}$ & 0.24 & 828 & 8866 & 43982 & 4108 & 38.47 \\
\hline $\begin{array}{l}1 / 3 \mathrm{CaHg}_{3}+4 / 9 \mathrm{Ca} \rightarrow \\
1 / 9 \mathrm{Ca}_{4} \mathrm{Hg}_{9}\end{array}$ & 0.46 & 28 & 319 & 1514 & 132 & 30.07 \\
\hline $1 / 3 \mathrm{CaHg}_{3}+1 / 6 \mathrm{Ca} \rightarrow 1 / 2 \mathrm{CaHg}_{2}$ & 0.46 & 42 & 479 & 2270 & 198 & 31.93 \\
\hline $1 / 3 \mathrm{CaHg}_{3}+2 / 3 \mathrm{Ca} \rightarrow \mathrm{CaHg}$ & 0.44 & 167 & 1915 & 9118 & 795 & 28.48 \\
\hline $\begin{array}{l}1 / 3 \mathrm{CaHg}_{3}+7 / 6 \mathrm{Ca} \rightarrow \\
1 / 2 \mathrm{Ca}_{3} \mathrm{Hg}_{2}\end{array}$ & 0.27 & 292 & 3352 & 16526 & 1440 & 35.36 \\
\hline $\begin{array}{l}1 / 3 \mathrm{CaHg}_{3}+4 / 3 \mathrm{Ca} \rightarrow \\
1 / 3 \mathrm{Ca}_{5} \mathrm{Hg}_{3}\end{array}$ & 0.24 & 334 & 3831 & 19009 & 1657 & 36.02 \\
\hline $1 / 3 \mathrm{CaHg}_{3}+8 / 3 \mathrm{Ca} \rightarrow \mathrm{Ca}_{3} \mathrm{Hg}$ & 0.12 & 668 & 7662 & 38923 & 3392 & 37.25 \\
\hline $\mathrm{Sb}+1 / 2 \mathrm{Ca} \rightarrow 1 / 2 \mathrm{CaSb}_{2}$ & 0.93 & 220 & 1444 & 6162 & 939 & 24.81 \\
\hline $\mathrm{Sb}+11 / 10 \mathrm{Ca} \rightarrow 1 / 10 \mathrm{Ca}_{11} \mathrm{Sb}_{10}$ & 0.92 & 484 & 3178 & 13617 & 2075 & 28.37 \\
\hline $\mathrm{Sb}+5 / 3 \mathrm{Ca} \rightarrow 1 / 3 \mathrm{Ca}_{5} \mathrm{Sb}_{3}$ & 0.80 & 734 & 4815 & 21190 & 3229 & 31.14 \\
\hline $\mathrm{Sb}+2 \mathrm{Ca} \rightarrow \mathrm{Ca}_{2} \mathrm{Sb}$ & 0.67 & 880 & 5778 & 26156 & 3985 & 29.66 \\
\hline $\mathrm{Au}+1 / 5 \mathrm{Ca} \rightarrow 1 / 5 \mathrm{CaAu}_{5}$ & 1.26 & 54 & 1055 & 4159 & 214 & 31.91 \\
\hline $\mathrm{Au}+1 / 2 \mathrm{Ca} \rightarrow 1 / 2 \mathrm{CaAu}_{2}$ & 1.08 & 136 & 2638 & 10870 & 561 & 32.08 \\
\hline $\mathrm{Au}+3 / 4 \mathrm{Ca} \rightarrow 1 / 4 \mathrm{Ca}_{3} \mathrm{Au}_{4}$ & 0.93 & 204 & 3958 & 16907 & 872 & 31.14 \\
\hline $\mathrm{Au}+1 \mathrm{Ca} \rightarrow \mathrm{CaAu}$ & 0.82 & 272 & 5277 & 23107 & 1192 & 33.32 \\
\hline $\mathrm{Au}+5 / 4 \mathrm{Ca} \rightarrow 1 / 4 \mathrm{Ca}_{5} \mathrm{Au}_{4}$ & 0.70 & 340 & 6596 & 29688 & 1531 & 33.50 \\
\hline $\mathrm{Au}+5 / 3 \mathrm{Ca} \rightarrow 1 / 3 \mathrm{Ca}_{5} \mathrm{Au}_{3}$ & 0.56 & 454 & 8795 & 40824 & 2105 & 34.41 \\
\hline $\mathrm{Au}+7 / 3 \mathrm{Ca} \rightarrow 1 / 3 \mathrm{Ca}_{7} \mathrm{Au}_{3}$ & 0.42 & 635 & 12312 & 58915 & 3038 & 37.30 \\
\hline $\mathrm{Au}+5 / 2 \mathrm{Ca} \rightarrow 1 / 2 \mathrm{Ca}_{5} \mathrm{Au}_{2}$ & 0.40 & 680 & 13192 & 63387 & 3269 & 37.35 \\
\hline $\mathrm{Au}+3 \mathrm{Ca} \rightarrow \mathrm{Ca}_{3} \mathrm{Au}$ & 0.33 & 816 & 15830 & 77078 & 3975 & 38.42 \\
\hline $\mathrm{Tl}+1 / 3 \mathrm{Ca} \rightarrow 1 / 3 \mathrm{CaTl}_{3}$ & 0.48 & 87 & 1021 & 4818 & 413 & 23.11 \\
\hline $\mathrm{Tl}+3 / 5 \mathrm{Ca} \rightarrow 1 / 5 \mathrm{Ca}_{3} \mathrm{Tl}_{5}$ & 0.46 & 157 & 1837 & 8703 & 745 & 27.28 \\
\hline
\end{tabular}




\begin{tabular}{|c|c|c|c|c|c|c|}
\hline $\mathrm{Tl}+1 \mathrm{Ca} \rightarrow \mathrm{CaTl}$ & 0.45 & 262 & 3062 & 14533 & 1245 & 27.86 \\
\hline $\mathrm{Tl}+3 \mathrm{Ca} \rightarrow \mathrm{Ca}_{3} \mathrm{Tl}$ & 0.15 & 787 & 9185 & 46373 & 3972 & 30.62 \\
\hline $\mathrm{Pb}+1 / 3 \mathrm{Ca} \rightarrow 1 / 3 \mathrm{CaPb}_{3}$ & 0.67 & 86 & 989 & 4474 & 390 & 27.40 \\
\hline $\mathrm{Pb}+1 \mathrm{Ca} \rightarrow \mathrm{CaPb}$ & 0.53 & 259 & 2966 & 13846 & 1208 & 28.81 \\
\hline $\mathrm{Pb}+5 / 3 \mathrm{Ca} \rightarrow 1 / 3 \mathrm{Ca}_{5} \mathrm{~Pb}_{3}$ & 0.45 & 431 & 4943 & 23497 & 2050 & 35.53 \\
\hline $\mathrm{Pb}+2 \mathrm{Ca} \rightarrow \mathrm{Ca}_{2} \mathrm{~Pb}$ & 0.43 & 517 & 5931 & 28321 & 2470 & 34.64 \\
\hline $\mathrm{Pb}+3 \mathrm{Ca} \rightarrow \mathrm{Ca}_{3} \mathrm{~Pb}$ & 0.28 & 776 & 8897 & 43744 & 3816 & 28.10 \\
\hline $\mathrm{Cd}+1 / 2 \mathrm{Ca} \rightarrow 1 / 2 \mathrm{CaCd}_{2}$ & 0.53 & 238 & 2076 & 9700 & 1114 & 35.54 \\
\hline $\mathrm{Cd}+1 \mathrm{Ca} \rightarrow \mathrm{CaCd}$ & 0.37 & 477 & 4152 & 20035 & 2301 & 35.14 \\
\hline $\mathrm{Cd}+3 / 2 \mathrm{Ca} \rightarrow 1 / 2 \mathrm{Ca}_{3} \mathrm{Cd}_{2}$ & 0.26 & 715 & 6227 & 30788 & 3536 & 38.22 \\
\hline $\mathrm{Pt}+1 / 5 \mathrm{Ca} \rightarrow 1 / 5 \mathrm{CaPt}_{5}$ & 1.60 & 55 & 1179 & 4242 & 198 & 31.66 \\
\hline $\mathrm{Pt}+1 / 2 \mathrm{Ca} \rightarrow 1 / 2 \mathrm{CaPt}_{2}$ & 1.43 & 137 & 2948 & 11124 & 518 & 24.63 \\
\hline $\mathrm{Pt}+3 / 2 \mathrm{Ca} \rightarrow 1 / 2 \mathrm{Ca}_{3} \mathrm{Pt}_{2}$ & 0.73 & 412 & 8843 & 39553 & 1843 & 31.83 \\
\hline $\mathrm{Pt}+5 / 3 \mathrm{Ca} \rightarrow 1 / 3 \mathrm{Ca}_{5} \mathrm{Pt}_{3}$ & 0.67 & 458 & 9825 & 44498 & 2074 & 29.40 \\
\hline$\underline{\mathrm{Pt}}+5 / 2 \mathrm{Ca} \rightarrow 1 / 2 \mathrm{Ca}_{5} \mathrm{Pt}_{2}$ & 0.50 & 687 & 14738 & 69208 & 3225 & 34.62 \\
\hline $\mathrm{Sn}+1 / 3 \mathrm{Ca} \rightarrow 1 / 2 \mathrm{CaSn}_{3}$ & 0.99 & 150 & 875 & 3682 & 633 & 7.43 \\
\hline $\mathrm{Sn}+1 \mathrm{Ca} \rightarrow \mathrm{CaSn}$ & 0.72 & 451 & 2624 & 11746 & 2020 & 27.51 \\
\hline $\mathrm{Sn}+7 / 6 \mathrm{Ca} \rightarrow 1 / 6 \mathrm{Ca}_{7} \mathrm{Sn}_{6}$ & 0.59 & 527 & 3062 & 14109 & 2426 & 27.59 \\
\hline $\mathrm{Sn}+31 / 20 \mathrm{Ca} \rightarrow 1 / 20 \mathrm{Ca}_{31} \mathrm{Sn}_{20}$ & 0.59 & 700 & 4068 & 18744 & 3224 & 28.87 \\
\hline $\mathrm{Sn}+36 / 23 \mathrm{Ca} \rightarrow 1 / 23 \mathrm{Ca} \mathrm{a}_{36} \mathrm{Sn}_{23}$ & 0.53 & 706 & 4108 & 19185 & 3300 & 27.99 \\
\hline $\mathrm{Sn}+2 \mathrm{Ca} \rightarrow \mathrm{Ca}_{2} \mathrm{Sn}$ & 0.53 & 903 & 5249 & 24515 & 4216 & 31.13 \\
\hline
\end{tabular}


Table S2. Full reaction pathways for candidates with restrictive voltage constraint $\left(\mathrm{V}_{\text {threshold }}\right.$

$=\mathbf{0 . 5 3} \mathrm{V})$. For each reaction of specific candidate system, we show the reactant, product, voltage, gravimetric capacity, volumetric capacity, energy density, specific energy, and volume expansion.

\begin{tabular}{|c|c|c|c|c|c|c|}
\hline Candidates and reactions & $\begin{array}{l}\text { Calciation } \\
\text { voltages } \\
\text { (V) }\end{array}$ & $\begin{array}{c}\text { Gravimetric } \\
\text { Capacity } \\
\text { (mAh/g) }\end{array}$ & $\begin{array}{c}\text { Volumetric } \\
\text { Capacity } \\
(\mathrm{mAh} / \mathrm{mL})\end{array}$ & $\begin{array}{l}\text { Energy } \\
\text { Density } \\
(\mathrm{Wh} / \mathrm{L})\end{array}$ & $\begin{array}{c}\text { Specific } \\
\text { Energy } \\
(\mathrm{Wh} / \mathrm{kg})\end{array}$ & $\begin{array}{c}\text { Volume } \\
\text { Expansion } \\
\text { per } \mathrm{Ca} / \AA^{3}\end{array}$ \\
\hline $\mathrm{Si}+1 / 2 \mathrm{Ca} \rightarrow 1 / 2 \mathrm{CaSi}_{2}$ & 0.58 & 954 & 2223 & 10261 & 4404 & 27.29 \\
\hline $\mathrm{Si}+14 / 19 \mathrm{Ca} \rightarrow 1 / 19 \mathrm{Ca}_{14} \mathrm{Si}_{19}$ & 0.56 & 1406 & 3276 & 15193 & 6522 & 26.04 \\
\hline $\mathrm{Si}+\mathrm{Ca} \rightarrow \mathrm{CaSi}$ & 0.55 & 1908 & 4446 & 20673 & 8874 & 27.60 \\
\hline $\mathrm{As}+1 / 3 \mathrm{Ca} \rightarrow 1 / 3 \mathrm{CaAs}_{3}$ & 1.14 & 238 & 1378 & 5599 & 969 & 27.41 \\
\hline $\mathrm{As}+2 / 3 \mathrm{Ca} \rightarrow 1 / 3 \mathrm{Ca}_{2} \mathrm{As}_{3}$ & 1.12 & 477 & 2757 & 11257 & 1947 & 27.25 \\
\hline $\mathrm{As}+1 \mathrm{Ca} \rightarrow \mathrm{CaAs}$ & 1.10 & 715 & 4135 & 16947 & 2932 & 31.03 \\
\hline $\mathrm{As}+5 / 3 \mathrm{Ca} \rightarrow 1 / 3 \mathrm{Ca}_{5} \mathrm{As}_{3}$ & 0.90 & 1192 & 6892 & 29665 & 5132 & 28.63 \\
\hline $\mathrm{As}+2 \mathrm{Ca} \rightarrow \mathrm{Ca}_{2} \mathrm{As}$ & 0.75 & 1431 & 8271 & 36830 & 6371 & 30.93 \\
\hline $\mathrm{Sb}+1 / 2 \mathrm{Ca} \rightarrow 1 / 2 \mathrm{CaSb}_{2}$ & 0.93 & 220 & 1444 & 6162 & 939 & 24.81 \\
\hline $\mathrm{Sb}+11 / 10 \mathrm{Ca} \rightarrow 1 / 10 \mathrm{Ca}_{11} \mathrm{Sb}_{10}$ & 0.92 & 484 & 3178 & 13617 & 2075 & 28.37 \\
\hline $\mathrm{Sb}+5 / 3 \mathrm{Ca} \rightarrow 1 / 3 \mathrm{Ca}_{5} \mathrm{Sb}_{3}$ & 0.80 & 734 & 4815 & 21190 & 3229 & 31.14 \\
\hline $\mathrm{Sb}+2 \mathrm{Ca} \rightarrow \mathrm{Ca}_{2} \mathrm{Sb}$ & 0.67 & 880 & 5778 & 26156 & 3985 & 29.66 \\
\hline $\mathrm{Pd}+1 / 5 \mathrm{Ca} \rightarrow 1 / 5 \mathrm{CaPd}_{5}$ & 1.12 & 101 & 1209 & 4938 & 411 & 23.32 \\
\hline $\mathrm{Pd}+1 / 2 \mathrm{Ca} \rightarrow 1 / 2 \mathrm{CaPd}_{2}$ & 1.07 & 252 & 3023 & 12490 & 1040 & 26.86 \\
\hline $\mathrm{Pd}+1 \mathrm{Ca} \rightarrow \mathrm{CaPd}$ & 0.69 & 504 & 6047 & 27284 & 2272 & 28.82 \\
\hline$\underline{\mathrm{Pd}+3 / 2 \mathrm{Ca} \rightarrow 1 / 2 \mathrm{Ca}_{3} \mathrm{Pd}_{2}}$ & 0.54 & 755 & 9070 & 42259 & 3520 & 33.50 \\
\hline $\mathrm{Ge}+1 / 2 \mathrm{Ca} \rightarrow 1 / 2 \mathrm{CaGe}_{2}$ & 0.74 & 369 & 1966 & 8764 & 1645 & 24.91 \\
\hline $\mathrm{Ge}+1 \mathrm{Ca} \rightarrow \mathrm{CaGe}$ & 0.67 & 738 & 3932 & 17799 & 3340 & 26.90 \\
\hline $\mathrm{Bi}+11 / 10 \mathrm{Ca} \rightarrow 1 / 10 \mathrm{Ca}_{11} \mathrm{Bi}_{10}$ & 0.79 & 282 & 2767 & 12199 & 1244 & 28.21 \\
\hline $\mathrm{Bi}+5 / 3 \mathrm{Ca} \rightarrow 1 / 3 \mathrm{Ca}_{5} \mathrm{Bi}_{3}$ & 0.68 & 427 & 4192 & 18932 & 1930 & 30.61 \\
\hline $\mathrm{Bi}+2 \mathrm{Ca} \rightarrow \mathrm{Ca}_{2} \mathrm{Bi}$ & 0.59 & 513 & 5031 & 23206 & 2366 & 28.37 \\
\hline $\mathrm{Pt}+1 / 5 \mathrm{Ca} \rightarrow 1 / 5 \mathrm{CaPt}_{5}$ & 1.60 & 55 & 1179 & 4242 & 198 & 31.66 \\
\hline $\mathrm{Pt}+1 / 2 \mathrm{Ca} \rightarrow 1 / 2 \mathrm{CaPt}_{2}$ & 1.43 & 137 & 2948 & 11124 & 518 & 24.63 \\
\hline $\mathrm{Pt}+3 / 2 \mathrm{Ca} \rightarrow 1 / 2 \mathrm{Ca}_{3} \mathrm{Pt}_{2}$ & 0.73 & 412 & 8843 & 39553 & 1843 & 31.83 \\
\hline $\mathrm{Pt}+5 / 3 \mathrm{Ca} \rightarrow 1 / 3 \mathrm{Ca}_{5} \mathrm{Pt}_{3}$ & 0.67 & 458 & 9825 & 44498 & 2074 & 29.40 \\
\hline $\mathrm{Au}+1 / 5 \mathrm{Ca} \rightarrow 1 / 5 \mathrm{CaAu}_{5}$ & 1.26 & 54 & 1055 & 4159 & 214 & 31.91 \\
\hline $\mathrm{Au}+1 / 2 \mathrm{Ca} \rightarrow 1 / 2 \mathrm{CaAu}_{2}$ & 1.08 & 136 & 2638 & 10870 & 561 & 32.08 \\
\hline $\mathrm{Au}+3 / 4 \mathrm{Ca} \rightarrow 1 / 4 \mathrm{Ca}_{3} \mathrm{Au}_{4}$ & 0.93 & 204 & 3958 & 16907 & 872 & 31.14 \\
\hline $\mathrm{Au}+1 \mathrm{Ca} \rightarrow \mathrm{CaAu}$ & 0.82 & 272 & 5277 & 23107 & 1192 & 33.32 \\
\hline $\mathrm{Au}+5 / 4 \mathrm{Ca} \rightarrow 1 / 4 \mathrm{Ca}_{5} \mathrm{Au}_{4}$ & 0.70 & 340 & 6596 & 29688 & 1531 & 33.50 \\
\hline $\mathrm{Au}+5 / 3 \mathrm{Ca} \rightarrow 1 / 3 \mathrm{Ca}_{5} \mathrm{Au}_{3}$ & 0.56 & 454 & 8795 & 40824 & 2105 & 34.41 \\
\hline $\mathrm{Sn}+1 / 3 \mathrm{Ca} \rightarrow 1 / 3 \mathrm{CaSn}_{3}$ & 0.99 & 150 & 875 & 3682 & 633 & 7.43 \\
\hline $\mathrm{Sn}+1 \mathrm{Ca} \rightarrow \mathrm{CaSn}$ & 0.72 & 451 & 2624 & 11746 & 2020 & 27.51 \\
\hline
\end{tabular}


$\mathrm{Sn}+7 / 6 \mathrm{Ca} \rightarrow 1 / 6 \mathrm{Ca}_{7} \mathrm{Sn}_{6}$

0.59

527

3062

14109

2426

27.59 
Table S3. Non-candidate compounds with relaxed voltage constraint $\left(\mathrm{V}_{\text {threshold }}=\mathbf{0 . 1 V}\right)$. For each reaction compound system, we show the reactant, product, voltage, gravimetric capacity, volumetric capacity, energy density, specific energy, and volume expansion.

\begin{tabular}{|c|c|c|c|c|c|c|}
\hline Candidates and reactions & $\begin{array}{l}\text { Averaged } \\
\text { calciation } \\
\text { voltage (V) }\end{array}$ & $\begin{array}{c}\text { Gravimetric } \\
\text { Capacity } \\
(\mathrm{mAh} / \mathrm{g})\end{array}$ & $\begin{array}{c}\text { Volumetric } \\
\text { Capacity } \\
(\mathrm{mAh} / \mathrm{mL})\end{array}$ & $\begin{array}{l}\text { Energy } \\
\text { Density } \\
(\mathrm{Wh} / \mathrm{L})\end{array}$ & $\begin{array}{l}\text { Specific } \\
\text { Energy } \\
(\mathrm{Wh} / \mathrm{kg})\end{array}$ & $\begin{array}{c}\text { Volume } \\
\text { Expansion } \\
\text { per } \mathrm{Ca} / \AA^{3}\end{array}$ \\
\hline $\mathrm{Bi}+2 \mathrm{Ca} \rightarrow \mathrm{Ca}_{2} \mathrm{Bi}$ & 0.59 & 513 & 5031 & 23206 & 2366 & 28.37 \\
\hline $\mathrm{Ni}+1 / 2 \mathrm{Ca} \rightarrow 1 / 2 \mathrm{CaNi}_{2}$ & 0.27 & 457 & 4116 & 20276 & 2249 & 25.80 \\
\hline $\mathrm{Be}+1 / 13 \mathrm{Ca} \rightarrow 1 / 13 \mathrm{CaBe}_{13}$ & 0.68 & 457 & 811 & 3662 & 2067 & 27.30 \\
\hline $\mathrm{Te}+\mathrm{Ca} \rightarrow \mathrm{CaTe}$ & 1.66 & 420 & 2615 & 9255 & 1486 & 30.16 \\
\hline $\mathrm{Rh}+1 / 2 \mathrm{Ca} \rightarrow 1 / 2 \mathrm{CaRh}_{2}$ & 0.63 & 260 & 3844 & 17550 & 1189 & 30.11 \\
\hline $\mathrm{Ir}+1 / 2 \mathrm{Ca} \rightarrow 1 / 2 \mathrm{CaIr}_{2}$ & 0.70 & 139 & 3165 & 14250 & 628 & 25.57 \\
\hline $\mathrm{Mg}+1 / 2 \mathrm{Ca} \rightarrow 1 / 2 \mathrm{CaMg}_{2}$ & 0.19 & 1103 & 1979 & 9918 & 5525 & 41.62 \\
\hline $\mathrm{CaAl}_{2} \mathrm{Si}_{2}+2 \mathrm{Ca} \rightarrow \mathrm{Ca}_{3} \mathrm{Al}_{2} \mathrm{Si}_{2}$ & 0.40 & 713 & 1683 & 8080 & 3424 & 32.85 \\
\hline $\mathrm{Si}_{2} \mathrm{Ni}_{3}+3 \mathrm{Ca} \rightarrow \mathrm{Ca}_{3} \mathrm{Si}_{2} \mathrm{Ni}_{3}$ & 0.23 & 692 & 4696 & 23352 & 3442 & 34.08 \\
\hline $\mathrm{MnSi}+\mathrm{Ca} \rightarrow \mathrm{CaMnSi}$ & 0.15 & 645 & 3885 & 19604 & 3257 & 33.82 \\
\hline $\mathrm{SrSi}+\mathrm{Ca} \rightarrow \mathrm{CaSrSi}$ & 0.20 & 463 & 1607 & 8036 & 2316 & 35.41 \\
\hline $\begin{array}{l}\mathrm{GaPd}+3 / 2 \mathrm{Ca} \rightarrow 1 / 2 \\
\mathrm{Ca}_{3} \mathrm{Ga}_{2} \mathrm{Pd}_{2} \\
\end{array}$ & 0.40 & 456 & 4389 & 21052 & 2189 & 33.48 \\
\hline $\mathrm{SiAs}_{2}+3 / 2 \mathrm{Ca} \rightarrow 1 / 2 \mathrm{Ca}_{3} \mathrm{Si}_{2} \mathrm{Ass}_{4}$ & 1.17 & 452 & 1785 & 7198 & 1821 & 22.44 \\
\hline $\mathrm{CaAl}_{2} \mathrm{Ge}_{2}+2 \mathrm{Ca} \rightarrow \mathrm{Ca}_{3} \mathrm{Al}_{2} \mathrm{Ge}_{2}$ & 0.43 & 448 & 1631 & 7771 & 2134 & 32.86 \\
\hline $\mathrm{LiSn}+\mathrm{Ca} \rightarrow \mathrm{CaLiSn}$ & 0.52 & 417 & 2186 & 10225 & 1951 & 33.71 \\
\hline $\mathrm{CdAs}_{2}+2 \mathrm{Ca} \rightarrow \mathrm{Ca}_{2} \mathrm{CdAs}_{2}$ & 1.12 & 409 & 2320 & 9466 & 1667 & 25.76 \\
\hline $\mathrm{NiGe}+\mathrm{Ca} \rightarrow \mathrm{CaNiGe}$ & 0.53 & 408 & 3251 & 15182 & 1905 & 31.14 \\
\hline $\mathrm{AlPd}+\mathrm{Ca} \rightarrow \mathrm{CaAlPd}$ & 0.20 & 402 & 3037 & 15170 & 2006 & 33.82 \\
\hline $\mathrm{SiPd}+\mathrm{Ca} \rightarrow \mathrm{CaSiPd}$ & 0.65 & 398 & 2985 & 13572 & 1811 & 28.93 \\
\hline $\mathrm{CuAs}+\mathrm{Ca} \rightarrow \mathrm{CaCuAs}$ & 1.24 & 387 & 2775 & 10982 & 1531 & 27.52 \\
\hline $\mathrm{SiNi}_{2}+\mathrm{Ca} \rightarrow \mathrm{CaSiNi}_{2}$ & 0.25 & 368 & 2711 & 13418 & 1823 & 34.64 \\
\hline $\begin{array}{l}\mathrm{GeAs}_{2}+3 / 2 \mathrm{Ca} \rightarrow \\
1 / 2 \mathrm{Ca}_{3} \mathrm{Ge}_{2} \mathrm{As} 4 \\
\end{array}$ & 1.11 & 361 & 1749 & 7151 & 1477 & 24.01 \\
\hline $\mathrm{SrGe}+\mathrm{Ca} \rightarrow \mathrm{CaSrGe}$ & 0.29 & 334 & 1524 & 7488 & 1642 & 34.07 \\
\hline $\mathrm{RbAs}+\mathrm{Ca} \rightarrow \mathrm{CaRbAs}$ & 0.86 & 334 & 1233 & 5357 & 1451 & 34.49 \\
\hline $\mathrm{InPd}_{2}+2 \mathrm{Ca} \rightarrow \mathrm{Ca}_{2} \mathrm{InPd}_{2}$ & 0.53 & 327 & 3535 & 16499 & 1526 & 32.89 \\
\hline $\mathrm{BaSi}+\mathrm{Ca} \rightarrow \mathrm{CaBaSi}$ & 0.19 & 324 & 1399 & 7004 & 1621 & 35.81 \\
\hline $\mathrm{GaNi}+3 / 4 \mathrm{Ca} \rightarrow 1 / 4 \mathrm{Ca}_{3} \mathrm{Ga}_{4} \mathrm{Ni}_{4}$ & 0.37 & 313 & 1797 & 8680 & 1512 & 17.96 \\
\hline $\mathrm{SiNi}+1 / 2 \mathrm{Ca} \rightarrow 1 / 2 \mathrm{CaSi}_{2} \mathrm{Ni}_{2}$ & 0.59 & 309 & 1838 & 8465 & 1422 & 28.32 \\
\hline $\mathrm{CoSi}+1 / 2 \mathrm{Ca} \rightarrow 1 / 2 \mathrm{CaCO}_{2} \mathrm{Si}_{2}$ & 0.30 & 308 & 2058 & 10077 & 1508 & 35.80 \\
\hline
\end{tabular}




\begin{tabular}{|c|c|c|c|c|c|c|}
\hline $\mathrm{CuSn}+\mathrm{Ca} \rightarrow \mathrm{CaCuSn}$ & 0.67 & 294 & 2326 & 10532 & 1331 & 28.35 \\
\hline $\mathrm{NiGe}_{2}+\mathrm{Ca} \rightarrow \mathrm{CaNiGe}_{2}$ & 0.76 & 263 & 1937 & 8595 & 1165 & 28.31 \\
\hline $\mathrm{SrSn}+\mathrm{Ca} \rightarrow \mathrm{CaSrSn}$ & 0.33 & 260 & 1274 & 6203 & 1264 & 35.06 \\
\hline $\mathrm{RbSb}+\mathrm{Ca} \rightarrow \mathrm{CaRbSb}$ & 0.77 & 259 & 993 & 4398 & 1145 & 34.79 \\
\hline$\underline{\mathrm{BaGe}}+\mathrm{Ca} \rightarrow \mathrm{CaBaGe}$ & 0.27 & 255 & 1329 & 6546 & 1257 & 34.36 \\
\hline $\mathrm{LiPb}+\mathrm{Ca} \rightarrow \mathrm{CaLiPb}$ & 0.43 & 250 & 2004 & 9565 & 1194 & 32.63 \\
\hline $\mathrm{LiBi}+\mathrm{Ca} \rightarrow \mathrm{CaLiBi}$ & 0.82 & 248 & 1885 & 8254 & 1086 & 30.49 \\
\hline $\mathrm{InRh}+\mathrm{Ca} \rightarrow \mathrm{CaInRh}$ & 0.40 & 246 & 2613 & 12551 & 1182 & 32.40 \\
\hline $\mathrm{InPd}+\mathrm{Ca} \rightarrow \mathrm{CaInPd}$ & 0.58 & 242 & 2480 & 11465 & 1120 & 32.79 \\
\hline $\mathrm{AlPt}+\mathrm{Ca} \rightarrow \mathrm{CaAlPt}$ & 0.42 & 241 & 3000 & 14336 & 1153 & 31.31 \\
\hline $\mathrm{SiPt}+\mathrm{Ca} \rightarrow \mathrm{CaSiPt}$ & 0.81 & 240 & 2908 & 12767 & 1054 & 34.14 \\
\hline $\mathrm{AlAu}+\mathrm{Ca} \rightarrow \mathrm{CaAlAu}$ & 0.65 & 239 & 2547 & 11597 & 1089 & 29.85 \\
\hline $\mathrm{SnPd}+\mathrm{Ca} \rightarrow \mathrm{CaSnPd}$ & 0.69 & 238 & 2270 & 10232 & 1073 & 29.27 \\
\hline $\begin{array}{l}1 / 2 \mathrm{CaZn}_{2} \mathrm{Si}_{2}+1 / 2 \mathrm{Ca} \rightarrow \\
\mathrm{CaZnSi}\end{array}$ & 0.62 & 236 & 974 & 4458 & 1080 & 35.31 \\
\hline $\mathrm{InAu}_{3}+3 \mathrm{Ca} \rightarrow \mathrm{Ca}_{3} \mathrm{InAu}_{3}$ & 0.81 & 228 & 3568 & 15645 & 999 & 32.94 \\
\hline $\mathrm{Kbi}+\mathrm{Ca} \rightarrow \mathrm{CaKBi}$ & 0.68 & 216 & 1051 & 4752 & 977 & 39.95 \\
\hline $\mathrm{BaSn}+\mathrm{Ca} \rightarrow \mathrm{CaBaSn}$ & 0.31 & 209 & 1112 & 5441 & 1024 & 34.67 \\
\hline $\begin{array}{l}\mathrm{MnAs}+1 / 2 \mathrm{Ca} \rightarrow \\
1 / 2 \mathrm{CaMn}_{2} \mathrm{As}_{2} \\
\end{array}$ & 0.83 & 206 & 1567 & 6848 & 902 & 39.53 \\
\hline $\mathrm{FeAs}+1 / 2 \mathrm{Ca} \rightarrow 1 / 2 \mathrm{CaFe}_{2} \mathrm{As}_{2}$ & 0.94 & 205 & 1663 & 7078 & 872 & 28.69 \\
\hline $\begin{array}{l}\mathrm{CoGe}+1 / 2 \mathrm{Ca} \rightarrow \\
1 / 2 \mathrm{CaCO}_{2} \mathrm{Ge}_{2} \\
\end{array}$ & 0.77 & 204 & 1669 & 7400 & 903 & 28.12 \\
\hline $\mathrm{GaAu}+\mathrm{Ca} \rightarrow \mathrm{CaGaAu}$ & 0.85 & 201 & 2417 & 10501 & 873 & 28.54 \\
\hline $\mathrm{NiAs}+1 / 2 \mathrm{Ca} \rightarrow 1 / 2 \mathrm{CaNi}_{2} \mathrm{As}_{2}$ & 1.09 & 200 & 1544 & 6350 & 825 & 25.36 \\
\hline $\mathrm{CoAs}+1 / 2 \mathrm{Ca} \rightarrow 1 / 2 \mathrm{CaCo}_{2} \mathrm{As}_{2}$ & 0.94 & 200 & 1665 & 7089 & 852 & 28.51 \\
\hline $\mathrm{GePt}+\mathrm{Ca} \rightarrow \mathrm{CaGePt}$ & 0.88 & 200 & 2653 & 11451 & 864 & 26.42 \\
\hline $\mathrm{GePt}+\mathrm{Ca} \rightarrow \mathrm{CaGePt}$ & 0.91 & 200 & 2653 & 11383 & 859 & 26.42 \\
\hline $\mathrm{CuBi}+\mathrm{Ca} \rightarrow \mathrm{CaCuBi}$ & 0.76 & 197 & 1988 & 8832 & 873 & 29.12 \\
\hline \begin{tabular}{l|}
$\mathrm{Si}_{3} \mathrm{Ir}+\mathrm{Ca} \rightarrow \mathrm{CaSi}_{3} \mathrm{Ir}$ \\
\end{tabular} & 0.74 & 194 & 1398 & 6237 & 865 & 24.41 \\
\hline $\mathrm{ZnAs}+1 / 2 \mathrm{Ca} \rightarrow 1 / 2 \mathrm{CaZn}_{2} \mathrm{As}_{2}$ & 1.34 & 191 & 1118 & 4320 & 738 & 26.24 \\
\hline $\mathrm{GaAs}+1 / 2 \mathrm{Ca} \rightarrow 1 / 2 \mathrm{CaGa}_{2} \mathrm{As}_{2}$ & 0.91 & 185 & 942 & 4043 & 795 & 23.26 \\
\hline $\mathrm{In}_{2} \mathrm{Cu}+\mathrm{Ca} \rightarrow \mathrm{CaIn} 2 \mathrm{Cu}$ & 0.65 & 183 & 1364 & 6204 & 831 & 24.97 \\
\hline 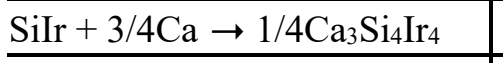 & 0.67 & 182 & 2313 & 10475 & 826 & 31.04 \\
\hline $\mathrm{SrPb}+\mathrm{Ca} \rightarrow \mathrm{CaSrPb}$ & 0.33 & 182 & 1225 & 5969 & 885 & 35.52 \\
\hline $\begin{array}{l}1 / 2 \mathrm{CaMn}_{2} \mathrm{Ge}_{2}+1 / 2 \mathrm{Ca} \rightarrow \\
\mathrm{CaMnGe}\end{array}$ & 0.48 & 181 & 1005 & 4749 & 857 & 23.21 \\
\hline $\mathrm{PbAu}_{2}+2 \mathrm{Ca} \rightarrow \mathrm{Ca}_{2} \mathrm{PbAu}_{2}$ & 0.84 & 178 & 2722 & 11862 & 777 & 30.54 \\
\hline $\mathrm{CdAu}+\mathrm{Ca} \rightarrow \mathrm{CaCdAu}$ & 0.78 & 173 & 2323 & 10274 & 766 & 33.35 \\
\hline $\mathrm{InNi}_{2}+3 / 4 \mathrm{Ca} \rightarrow 1 / 4 \mathrm{Ca}_{3} \mathrm{In}_{4} \mathrm{Ni}_{8}$ & 0.37 & 173 & 1591 & 7675 & 835 & 31.90 \\
\hline
\end{tabular}




\begin{tabular}{|c|c|c|c|c|c|c|}
\hline $\mathrm{InPt}+\mathrm{Ca} \rightarrow \mathrm{CaInPt}$ & 0.78 & 173 & 2325 & 10271 & 764 & 29.82 \\
\hline $\begin{array}{l}1 / 2 \mathrm{CaCu}_{2} \mathrm{Ge}_{2}+1 / 2 \mathrm{Ca} \rightarrow \\
\mathrm{CaCuGe} \\
\end{array}$ & 0.48 & 171 & 1007 & 4751 & 809 & 25.47 \\
\hline $\mathrm{SnAu}+\mathrm{Ca} \rightarrow \mathrm{CaSnAu}$ & 0.92 & 170 & 1878 & 8043 & 727 & 32.55 \\
\hline $\mathrm{SbPt}+\mathrm{Ca} \rightarrow \mathrm{CaSbPt}$ & 1.04 & 169 & 2105 & 8757 & 703 & 25.73 \\
\hline $\mathrm{Sn}_{2} \mathrm{Rh}+\mathrm{Ca} \rightarrow \mathrm{CaSn}_{2} \mathrm{Rh}$ & 0.72 & 157 & 1480 & 6626 & 705 & 29.86 \\
\hline $\mathrm{Sn}_{2} \mathrm{Pd}+\mathrm{Ca} \rightarrow \mathrm{CaSn}_{2} \mathrm{Pd}$ & 0.76 & 156 & 1339 & 5938 & 691 & 27.56 \\
\hline $\begin{array}{l}\mathrm{GeRu}+1 / 2 \mathrm{Ca} \rightarrow \\
1 / 2 \mathrm{CaGe}_{2} \mathrm{Ru}_{2} \\
\end{array}$ & 0.69 & 154 & 1523 & 6869 & 696 & 33.59 \\
\hline \begin{tabular}{l|}
$\mathrm{GeRh}+1 / 2 \mathrm{Ca} \rightarrow$ \\
$1 / 2 \mathrm{CaGe}_{2} \mathrm{Rh}_{2}$ \\
\end{tabular} & 0.91 & 153 & 1439 & 6181 & 655 & 29.39 \\
\hline $\mathrm{AsRu}+1 / 2 \mathrm{Ca} \rightarrow 1 / 2 \mathrm{CaAs}_{2} \mathrm{Ru}_{2}$ & 1.04 & 152 & 1444 & 6013 & 634 & 29.83 \\
\hline \begin{tabular}{l|l}
$\mathrm{MnSb}+1 / 2 \mathrm{Ca} \rightarrow$ \\
$1 / 2 \mathrm{CaMn}_{2} \mathrm{Sb}_{2}$
\end{tabular} & 0.87 & 152 & 1102 & 4777 & 657 & 48.05 \\
\hline $\mathrm{Al}_{9} \mathrm{Co}_{2}+\mathrm{Ca} \rightarrow \mathrm{CaAl}_{9} \mathrm{Co}_{2}$ & 0.51 & 149 & 538 & 2523 & 697 & 41.13 \\
\hline $\mathrm{ZnSb}+1 / 2 \mathrm{Ca} \rightarrow 1 / 2 \mathrm{CaZn}_{2} \mathrm{Sb}_{2}$ & 1.05 & 143 & 892 & 3701 & 594 & 29.94 \\
\hline $\mathrm{CdAs}+1 / 2 \mathrm{Ca} \rightarrow 1 / 2 \mathrm{CaCd}_{2} \mathrm{As}_{2}$ & 0.77 & 143 & 919 & 4076 & 634 & 25.10 \\
\hline \begin{tabular}{l|l}
$1 / 2 \mathrm{CaAs}_{2} \mathrm{Pd}_{2}+1 / 2 \mathrm{Ca} \rightarrow$ \\
$\mathrm{CaAsPd}$
\end{tabular} & 0.97 & 133 & 930 & 3935 & 563 & 36.98 \\
\hline $\begin{array}{l}\mathrm{Cu}_{2} \mathrm{As}+1 / 2 \mathrm{Ca} \rightarrow \\
1 / 2 \mathrm{CaCu}_{4} \mathrm{As}_{2} \\
\end{array}$ & 1.21 & 133 & 1039 & 4144 & 529 & 26.82 \\
\hline $\mathrm{In}_{2} \mathrm{Ir}+\mathrm{Ca} \rightarrow \mathrm{CaIn} \mathrm{Ir}$ & 0.66 & 127 & 1462 & 6637 & 577 & 30.43 \\
\hline $\mathrm{In}_{2} \mathrm{Pt}+\mathrm{Ca} \rightarrow \mathrm{CaIn} 2 \mathrm{Pt}$ & 0.68 & 126 & 1334 & 6024 & 570 & 25.07 \\
\hline $\mathrm{In}_{2} \mathrm{Au}+\mathrm{Ca} \rightarrow \mathrm{CaIn}_{2} \mathrm{Au}$ & 0.72 & 126 & 1211 & 5427 & 563 & 22.33 \\
\hline $\mathrm{Sn}_{2} \mathrm{Ir}+\mathrm{Ca} \rightarrow \mathrm{CaSn}_{2} \mathrm{Ir}$ & 0.71 & 125 & 1347 & 6052 & 560 & 24.48 \\
\hline $\mathrm{CdSb}+1 / 2 \mathrm{Ca} \rightarrow 1 / 2 \mathrm{CaCd}_{2} \mathrm{Sb}_{2}$ & 1.08 & 114 & 756 & 3115 & 471 & 27.10 \\
\hline \begin{tabular}{l|}
$\mathrm{Al}_{2} \mathrm{Cu}+1 / 4 \mathrm{Ca} \rightarrow$ \\
$1 / 4 \mathrm{CaAl} \mathrm{Cu}_{4}$ \\
\end{tabular} & 0.63 & 114 & 465 & 2128 & 521 & 9.13 \\
\hline $\mathrm{BaSn}_{3}+\mathrm{Ca} \rightarrow \mathrm{CaBaSn}_{3}$ & 0.59 & 109 & 692 & 3192 & 501 & 36.32 \\
\hline $\mathrm{GeIr}+1 / 2 \mathrm{Ca} \rightarrow 1 / 2 \mathrm{CaGe}_{2} \mathrm{Ir}_{2}$ & 1.03 & 101 & 1392 & 5805 & 422 & 27.94 \\
\hline $\mathrm{In}_{3} \mathrm{Au}_{10}+4 \mathrm{Ca} \rightarrow \mathrm{Ca}_{4} \mathrm{In}_{3} \mathrm{Au}_{10}$ & 1.14 & 93 & 1475 & 5987 & 376 & 30.35 \\
\hline $\begin{array}{l}\mathrm{CaGaPt}+1 / 2 \mathrm{Ca} \rightarrow \\
1 / 2 \mathrm{Ca}_{3} \mathrm{Ga}_{2} \mathrm{Pt}_{2} \\
\end{array}$ & 0.24 & 88 & 731 & 3626 & 436 & 36.35 \\
\hline $\begin{array}{l}\mathrm{Bi}_{2} \mathrm{Pd}+3 / 4 \mathrm{Ca} \rightarrow \\
1 / 4 \mathrm{Ca}_{3} \mathrm{Bi}_{8} \mathrm{Pd}_{4} \\
\end{array}$ & 0.85 & 77 & 868 & 3775 & 333 & 28.58 \\
\hline $\begin{array}{l}1 / 2 \mathrm{Ca}_{5} \mathrm{Ga}_{2} \mathrm{As}_{6}+1 / 2 \mathrm{Ca} \rightarrow \\
\mathrm{Ca}_{3} \mathrm{GaAs}_{3}\end{array}$ & 0.91 & 68 & 282 & 1209 & 291 & 31.65 \\
\hline $\begin{array}{l}1 / 2 \mathrm{Ca}_{5} \mathrm{Al}_{2} \mathrm{Sb}_{3}+1 / 2 \mathrm{Ca} \rightarrow \\
\mathrm{Ca}_{3} \mathrm{AlSb}_{3}\end{array}$ & 0.82 & 54 & 231 & 1011 & 238 & 34.48 \\
\hline
\end{tabular}


Table S4. Non-candidate compounds with restrictive voltage constraint $\left(\mathrm{V}_{\text {threshold }}=\mathbf{0 . 5 3} \mathrm{V}\right)$.

For each compound system we show the reactant, final product, averaged voltage, gravimetric capacity, volumetric capacity, energy density, specific energy, and volume expansion maximum.

\begin{tabular}{|c|c|c|c|c|c|c|}
\hline Candidates and reactions & $\begin{array}{l}\text { Averaged } \\
\text { calciation } \\
\text { voltage (V) }\end{array}$ & $\begin{array}{c}\text { Gravimetric } \\
\text { Capacity } \\
(\mathrm{mAh} / \mathrm{g})\end{array}$ & $\begin{array}{c}\text { Volumetric } \\
\text { Capacity } \\
(\mathrm{mAh} / \mathrm{mL})\end{array}$ & $\begin{array}{l}\text { Energy } \\
\text { Density } \\
(\mathrm{Wh} / \mathrm{L})\end{array}$ & $\begin{array}{l}\text { Specific } \\
\text { Energy } \\
(\mathrm{Wh} / \mathrm{kg})\end{array}$ & $\begin{array}{l}\text { Volume } \\
\text { Expansion } \\
\text { per } \mathrm{Ca} / \AA^{3}\end{array}$ \\
\hline $\mathrm{InPd}_{2}+2 \mathrm{Ca} \rightarrow \mathrm{Ca}_{2} \mathrm{InPd}_{2}$ & 0.53 & 327 & 3535 & 16499 & 1526 & 32.89 \\
\hline $\mathrm{InAu}_{3}+3 \mathrm{Ca} \rightarrow \mathrm{Ca}_{3} \operatorname{InAu}_{3}$ & 0.81 & 228 & 3568 & 15645 & 999 & 32.94 \\
\hline $\mathrm{NiGe}+\mathrm{Ca} \rightarrow \mathrm{CaNiGe}$ & 0.53 & 408 & 3251 & 15182 & 1905 & 31.14 \\
\hline $\mathrm{SiPd}+\mathrm{Ca} \rightarrow \mathrm{CaSiPd}$ & 0.65 & 398 & 2985 & 13572 & 1811 & 28.93 \\
\hline $\mathrm{SiPt}+\mathrm{Ca} \rightarrow \mathrm{CaSiPt}$ & 0.81 & 240 & 2908 & 12767 & 1054 & 34.14 \\
\hline $\mathrm{PbAu}_{2}+2 \mathrm{Ca} \rightarrow \mathrm{Ca}_{2} \mathrm{PbAu}_{2}$ & 0.84 & 178 & 2722 & 11862 & 777 & 30.54 \\
\hline $\mathrm{Al} A u+\mathrm{Ca} \rightarrow \mathrm{CaAlAu}$ & 0.65 & 239 & 2547 & 11597 & 1089 & 29.85 \\
\hline $\mathrm{InPd}+\mathrm{Ca} \rightarrow \mathrm{CaInPd}$ & 0.58 & 242 & 2480 & 11465 & 1120 & 32.79 \\
\hline $\mathrm{GePt}+\mathrm{Ca} \rightarrow \mathrm{CaGePt}$ & 0.88 & 200 & 2653 & 11451 & 864 & 26.42 \\
\hline $\mathrm{GePt}+\mathrm{Ca} \rightarrow \mathrm{CaGePt}$ & 0.91 & 200 & 2653 & 11383 & 859 & 26.42 \\
\hline $\mathrm{CuAs}+\mathrm{Ca} \rightarrow \mathrm{CaCuAs}$ & 1.24 & 387 & 2775 & 10982 & 1531 & 27.52 \\
\hline $\mathrm{CuSn}+\mathrm{Ca} \rightarrow \mathrm{CaCuSn}$ & 0.67 & 294 & 2326 & 10532 & 1331 & 28.35 \\
\hline $\mathrm{GaAu}+\mathrm{Ca} \rightarrow \mathrm{CaGaAu}$ & 0.85 & 201 & 2417 & 10501 & 873 & 28.54 \\
\hline $\mathrm{SiIr}+3 / 4 \mathrm{Ca} \rightarrow 1 / 4 \mathrm{Ca}_{3} \mathrm{Si}_{4} \mathrm{Ir}_{4}$ & 0.67 & 182 & 2313 & 10475 & 826 & 31.04 \\
\hline $\mathrm{CdAu}+\mathrm{Ca} \rightarrow \mathrm{CaCdAu}$ & 0.78 & 173 & 2323 & 10274 & 766 & 33.35 \\
\hline $\mathrm{InPt}+\mathrm{Ca} \rightarrow \mathrm{CaInPt}$ & 0.78 & 173 & 2325 & 10271 & 764 & 29.82 \\
\hline $\mathrm{SnPd}+\mathrm{Ca} \rightarrow \mathrm{CaSnPd}$ & 0.69 & 238 & 2270 & 10232 & 1073 & 29.27 \\
\hline $\mathrm{CdAs}_{2}+2 \mathrm{Ca} \rightarrow \mathrm{Ca}_{2} \mathrm{CdAs}_{2}$ & 1.12 & 409 & 2320 & 9466 & 1667 & 25.76 \\
\hline $\mathrm{CuBi}+\mathrm{Ca} \rightarrow \mathrm{CaCuBi}$ & 0.76 & 197 & 1988 & 8832 & 873 & 29.12 \\
\hline $\mathrm{SbPt}+\mathrm{Ca} \rightarrow \mathrm{CaSbPt}$ & 1.04 & 169 & 2105 & 8757 & 703 & 25.73 \\
\hline $\mathrm{NiGe}_{2}+\mathrm{Ca} \rightarrow \mathrm{CaNiGe}_{2}$ & 0.76 & 263 & 1937 & 8595 & 1165 & 28.31 \\
\hline $\mathrm{SiNi}+1 / 2 \mathrm{Ca} \rightarrow 1 / 2 \mathrm{CaSi}_{2} \mathrm{Ni}_{2}$ & 0.59 & 309 & 1838 & 8465 & 1422 & 28.32 \\
\hline $\mathrm{LiBi}+\mathrm{Ca} \rightarrow \mathrm{CaLiBi}$ & 0.82 & 248 & 1885 & 8254 & 1086 & 30.49 \\
\hline $\mathrm{SnAu}+\mathrm{Ca} \rightarrow \mathrm{CaSnAu}$ & 0.92 & 170 & 1878 & 8043 & 727 & 32.55 \\
\hline $\begin{array}{l}\mathrm{CoGe}+1 / 2 \mathrm{Ca} \rightarrow \\
1 / 2 \mathrm{CaCo}_{2} \mathrm{Ge}_{2} \\
\end{array}$ & 0.77 & 204 & 1669 & 7400 & 903 & 28.12 \\
\hline $\mathrm{SiAs}_{2}+3 / 2 \mathrm{Ca} \rightarrow 1 / 2 \mathrm{Ca}_{3} \mathrm{Si}_{2} \mathrm{As}_{4}$ & 1.17 & 452 & 1785 & 7198 & 1821 & 22.44 \\
\hline \begin{tabular}{l|}
$\mathrm{GeAs}_{2}+3 / 2 \mathrm{Ca} \rightarrow$ \\
$1 / 2 \mathrm{Ca}_{3} \mathrm{Ge}_{2} \mathrm{As}_{4}$ \\
\end{tabular} & 1.11 & 361 & 1749 & 7151 & 1477 & 24.01 \\
\hline $\mathrm{CoAs}+1 / 2 \mathrm{Ca} \rightarrow 1 / 2 \mathrm{CaCo}_{2} \mathrm{As}_{2}$ & 0.94 & 200 & 1665 & 7089 & 852 & 28.51 \\
\hline $\mathrm{FeAs}+1 / 2 \mathrm{Ca} \rightarrow 1 / 2 \mathrm{CaFe}_{2} \mathrm{As}_{2}$ & 0.94 & 205 & 1663 & 7078 & 872 & 28.69 \\
\hline
\end{tabular}




\begin{tabular}{|c|c|c|c|c|c|c|}
\hline $\begin{array}{l}\mathrm{GeRu}+1 / 2 \mathrm{Ca} \rightarrow \\
1 / 2 \mathrm{CaGe}_{2} \mathrm{Ru}_{2}\end{array}$ & 0.69 & 154 & 1523 & 6869 & 696 & 33.59 \\
\hline $\begin{array}{l}\mathrm{MnAs}+1 / 2 \mathrm{Ca} \rightarrow \\
1 / 2 \mathrm{CaMn}_{2} \mathrm{As}_{2} \\
\end{array}$ & 0.83 & 206 & 1567 & 6848 & 902 & 39.53 \\
\hline $\mathrm{In}_{2} \mathrm{Ir}+\mathrm{Ca} \rightarrow \mathrm{CaIn}_{2} \mathrm{Ir}$ & 0.66 & 127 & 1462 & 6637 & 577 & 30.43 \\
\hline$\overline{\mathrm{Sn}_{2} \mathrm{Rh}+\mathrm{Ca} \rightarrow \mathrm{CaSn}_{2} \mathrm{Rh}}$ & 0.72 & 157 & 1480 & 6626 & 705 & 29.86 \\
\hline $\mathrm{NiAs}+1 / 2 \mathrm{Ca} \rightarrow 1 / 2 \mathrm{CaNi}_{2} \mathrm{As}_{2}$ & 1.09 & 200 & 1544 & 6350 & 825 & 25.36 \\
\hline $\mathrm{Si}_{3} \mathrm{Ir}+\mathrm{Ca} \rightarrow \mathrm{CaSi}_{3} \mathrm{Ir}$ & 0.74 & 194 & 1398 & 6237 & 865 & 24.41 \\
\hline $\mathrm{In}_{2} \mathrm{Cu}+\mathrm{Ca} \rightarrow \mathrm{CaIn}{ }_{2} \mathrm{Cu}$ & 0.65 & 183 & 1364 & 6204 & 831 & 24.97 \\
\hline $\begin{array}{l}\mathrm{GeRh}+1 / 2 \mathrm{Ca} \rightarrow \\
1 / 2 \mathrm{CaGe}_{2} \mathrm{Rh}_{2}\end{array}$ & 0.91 & 153 & 1439 & 6181 & 655 & 29.39 \\
\hline $\mathrm{Sn}_{2} \mathrm{Ir}+\mathrm{Ca} \rightarrow \mathrm{CaSn}_{2} \mathrm{Ir}$ & 0.71 & 125 & 1347 & 6052 & 560 & 24.48 \\
\hline $\mathrm{In}_{2} \mathrm{Pt}+\mathrm{Ca} \rightarrow \mathrm{CaIn}_{2} \mathrm{Pt}$ & 0.68 & 126 & 1334 & 6024 & 570 & 25.07 \\
\hline $\mathrm{AsRu}+1 / 2 \mathrm{Ca} \rightarrow 1 / 2 \mathrm{CaAs}_{2} \mathrm{Ru}_{2}$ & 1.04 & 152 & 1444 & 6013 & 634 & 29.83 \\
\hline $\mathrm{In}_{3} \mathrm{Au}_{10}+4 \mathrm{Ca} \rightarrow \mathrm{Ca}_{4} \mathrm{In}_{3} \mathrm{Au}_{10}$ & 1.14 & 93 & 1475 & 5987 & 376 & 30.35 \\
\hline $\mathrm{Sn}_{2} \mathrm{Pd}+\mathrm{Ca} \rightarrow \mathrm{CaSn}_{2} \mathrm{Pd}$ & 0.76 & 156 & 1339 & 5938 & 691 & 27.56 \\
\hline $\mathrm{GeIr}+1 / 2 \mathrm{Ca} \rightarrow 1 / 2 \mathrm{CaGe}_{2} \mathrm{Ir}_{2}$ & 1.03 & 101 & 1392 & 5805 & 422 & 27.94 \\
\hline $\mathrm{In}_{2} \mathrm{Au}+\mathrm{Ca} \rightarrow \mathrm{CaIn}_{2} \mathrm{Au}$ & 0.72 & 126 & 1211 & 5427 & 563 & 22.33 \\
\hline $\mathrm{RbAs}+\mathrm{Ca} \rightarrow \mathrm{CaRbAs}$ & 0.86 & 334 & 1233 & 5357 & 1451 & 34.49 \\
\hline $\begin{array}{l}\mathrm{MnSb}+1 / 2 \mathrm{Ca} \rightarrow \\
1 / 2 \mathrm{CaMn}_{2} \mathrm{Sb}_{2} \\
\end{array}$ & 0.87 & 152 & 1102 & 4777 & 657 & 48.05 \\
\hline $\mathrm{KBi}+\mathrm{Ca} \rightarrow \mathrm{CaKBi}$ & 0.68 & 216 & 1051 & 4752 & 977 & 39.95 \\
\hline $\begin{array}{l}1 / 2 \mathrm{CaZn}_{2} \mathrm{Si}_{2}+1 / 2 \mathrm{Ca} \rightarrow \\
\mathrm{CaZnSi}\end{array}$ & 0.62 & 236 & 974 & 4458 & 1080 & 35.31 \\
\hline $\mathrm{RbSb}+\mathrm{Ca} \rightarrow \mathrm{CaRbSb}$ & 0.77 & 259 & 993 & 4398 & 1145 & 34.79 \\
\hline $\mathrm{ZnAs}+1 / 2 \mathrm{Ca} \rightarrow 1 / 2 \mathrm{CaZn}_{2} \mathrm{As}_{2}$ & 1.34 & 191 & 1118 & 4320 & 738 & 26.24 \\
\hline \begin{tabular}{l|}
$\mathrm{Cu}_{2} \mathrm{As}+1 / 2 \mathrm{Ca} \rightarrow$ \\
$1 / 2 \mathrm{CaCu}_{4} \mathrm{As}_{2}$
\end{tabular} & 1.21 & 133 & 1039 & 4144 & 529 & 26.82 \\
\hline $\mathrm{CdAs}+1 / 2 \mathrm{Ca} \rightarrow 1 / 2 \mathrm{CaCd}_{2} \mathrm{As}_{2}$ & 0.77 & 143 & 919 & 4076 & 634 & 25.10 \\
\hline $\mathrm{GaAs}+1 / 2 \mathrm{Ca} \rightarrow 1 / 2 \mathrm{CaGa}_{2} \mathrm{As}_{2}$ & 0.91 & 185 & 942 & 4043 & 795 & 23.26 \\
\hline \begin{tabular}{l|l}
$1 / 2 \mathrm{CaAs}_{2} \mathrm{Pd}_{2}+1 / 2 \mathrm{Ca} \rightarrow$ \\
$\mathrm{CaAsPd}$
\end{tabular} & 0.97 & 133 & 930 & 3935 & 563 & 36.98 \\
\hline $\begin{array}{l}\mathrm{Bi}_{2} \mathrm{Pd}+3 / 4 \mathrm{Ca} \rightarrow \\
1 / 4 \mathrm{Ca}_{3} \mathrm{Bi}_{8} \mathrm{Pd}_{4} \\
\end{array}$ & 0.85 & 77 & 868 & 3775 & 333 & 28.58 \\
\hline $\mathrm{ZnSb}+1 / 2 \mathrm{Ca} \rightarrow 1 / 2 \mathrm{CaZn}_{2} \mathrm{Sb}_{2}$ & 1.05 & 143 & 892 & 3701 & 594 & 29.94 \\
\hline $\mathrm{BaSn}_{3}+\mathrm{Ca} \rightarrow \mathrm{CaBaSn}_{3}$ & 0.59 & 109 & 692 & 3192 & 501 & 36.32 \\
\hline $\mathrm{CdSb}+1 / 2 \mathrm{Ca} \rightarrow 1 / 2 \mathrm{CaCd}_{2} \mathrm{Sb}_{2}$ & 1.08 & 114 & 756 & 3115 & 471 & 27.10 \\
\hline \begin{tabular}{l|l}
$1 / 2 \mathrm{Ca}_{5} \mathrm{Ga}_{2} \mathrm{As}_{6}+1 / 2 \mathrm{Ca} \rightarrow$ \\
$\mathrm{Ca}_{3} \mathrm{GaAs}_{3}$
\end{tabular} & 0.91 & 68 & 282 & 1209 & 291 & 31.65 \\
\hline $\begin{array}{l}1 / 2 \mathrm{Ca}_{5} \mathrm{Al}_{2} \mathrm{Sb}_{6}+1 / 2 \mathrm{Ca} \rightarrow \\
\mathrm{Ca}_{3} \mathrm{AlSb}_{3}\end{array}$ & 0.82 & 54 & 231 & 1011 & 238 & 34.48 \\
\hline
\end{tabular}

